\title{
Imaging transcriptomics of brain disorders
}

\author{
Aurina Arnatkeviciute ${ }^{1}$, Ben D. Fulcher ${ }^{2}$, Mark A. Bellgrove ${ }^{1}$, and Alex Fornito ${ }^{1}$ \\ ${ }^{1}$ The Turner Institute for Brain and Mental Health, School of Psychological Sciences, Monash University, Victoria, Australia. \\ ${ }^{2}$ School of Physics, The University of Sydney, Camperdown, NSW 2006, Australia.
}

\begin{abstract}
Non-invasive neuroimaging is a powerful tool for quantifying diverse aspects of brain structure and function in vivo and has been used extensively to map the neural changes associated with different brain disorders. However, most neuroimaging techniques have limited spatiotemporal resolution and offer only indirect measures of underlying pathological mechanisms. The recent development of anatomically comprehensive gene-expression atlases has opened new opportunities for studying the transcriptional correlates of non-invasively measured neural phenotypes, offering a rich framework for evaluating pathophysiological hypotheses and putative mechanisms. Here, we overview some fundamental methods in imaging transcriptomics and outline their application to understanding brain disorders of neurodevelopment, adulthood, and neurodegeneration. Converging evidence indicates that spatial variations in gene expression are linked to normative changes in brain structure during agerelated maturation and neurodegeneration that are in part associated with cell-specific gene expression markers of gene expression. Transcriptional correlates of disorder-related neuroimaging phenotypes are also linked to transcriptionally dysregulated genes identified in ex vivo analyses of patient brains. Modeling studies demonstrate that spatial patterns of gene expression are involved in regional vulnerability to neurodegeneration and the spread of disease across the brain. This growing body of work supports the utility of transcriptional atlases in testing hypotheses about the molecular mechanism driving disease-related changes in macroscopic neuroimaging phenotypes.
\end{abstract}

Keywords: brain imaging, gene expression, connectome, psychiatric disorders, neurodevelopment, neurodegeneration 


\section{Introduction}

The advent of magnetic resonance imaging (MRI) ushered a new era of biological psychiatry, arming researchers with a powerful tool for studying the neural correlates of mental illness non-invasively. Thousands of research articles published in the intervening years have shed important light on the disruptions of brain structure and function that occur in association with a diverse range of psychiatric disorders. However, due to the limited spatiotemporal resolution of current MRI and other imaging methods and the biophysical properties of the acquired signals, the resulting imaging-derived phenotypes (IDPs) often represent indirect proxies for the cellular and molecular processes that ultimately drive disease pathophysiology. As a result, in vivo neuroimaging is an excellent tool for mapping where changes occur in the brain, and at which specific stage of disease, but it can offer only limited insight into the physiological mechanisms that underpin these changes.

Over the past two decades, imaging genetics has offered a means for studying the molecular basis of diseaserelated IDPs. A growing body of literature indicates that genetics play a substantial role in shaping how the brain is organized (Arnatkeviciute, Fulcher, Bellgrove, et al., 2021; Bigos \& Weinberger, 2010; Fornito et al., 2019; Hashimoto et al., 2015; Thompson et al., 2001, 2013). Heritability studies show that a range of IDPs are highly heritable (Arnatkeviciute, et al., 2021; Baaré et al., 2001; Ge et al., 2017; Pizzagalli et al., 2020; Shen et al., 2014; Thompson et al., 2013) and genome wide association studies (GWAS) have begun to identify robust links to DNA variation (Elliott et al., 2018; Hibar et al., 2015; Smith et al., 2021; Zhao et al., 2019), uncovering hundreds of associations between single nucleotide polymorphisms (SNPs) and diverse measures of brain structure, function, and connectivity (Elliott et al., 2018; Hibar et al., 2015, 2017; Jansen et al., 2019; Satizabal et al., 2019; Smith et al., 2020).

The general assumption in imaging genetics research is that DNA variants implicated in GWAS, or variants in linkage disequilibrium, impact protein expression and/or function, thereby influencing cellular form and physiology to give rise to phenotypic variability. However, multiple factors can influence the transcriptional activity of a gene and the subsequent abundance of its protein product (Choi \& Kim, 2007; Cole, 2009; Fraser et al., 2005), meaning that allelic variations of DNA can be somewhat distant from the molecular mechanisms influencing a particular phenotype. Studies of gene expression can more directly interrogate the transcriptional activity of genes, as measured in post-mortem specimens. Due to the complexities of tissue curation, processing, and analysis, such investigations have historically been limited to small subsets of brain regions, precluding an opportunity to link disease-related changes in gene expression to bran-wide IDPs. Over the past decade, advances in high-throughput tissue processing and analysis pipelines have facilitated the development of brain-wide geneexpression atlases (M. J. Hawrylycz et al., 2012; Lein et al., 2007), opening new opportunities to investigate how the spatial patterns of gene expression relate to anatomical variations in brain structure and function in both health and disease [for a review see (Fornito et al., 2019)]. Of particular relevance to psychiatry, this emerging field of imaging transcriptomics makes it possible to generate and test hypotheses about the transcriptional correlates of disease-related changes in IDPs, offering a bridge between molecular function and macroscale measures of brain dysfunction. 
In this review, we consider how imaging transcriptomics can shed light on putative pathophysiological mechanisms in psychiatric disorders. We first overview some fundamental methods in the field and then examine applications of these methods to understand neurodevelopment, neuropsychiatric illness, and neurodegeneration. These studies indicate that regional gene-expression patterns are related to normative changes in brain structure during age-related maturation and neurodegeneration. Genes related to synaptic signaling, metabolism, and other neurobiologically relevant categories are consistently associated with clinical alterations in neuropsychiatric disorders. Disorder-associated expression signatures tend to involve transcriptionally dysregulated genes in postmortem brain tissues of patients. Moreover, spatial patterns of gene expression play a role in both regional vulnerability to neurodegeneration and the spread of neurodegeneration across the brain. Finally, we discuss some methodological challenges and consider future directions for the field.

\section{Fundamental methods of imaging transcriptomics}

Brain-wide imaging transcriptomic studies rely on transcriptional atlases that assay gene expression across multiple locations in the brain. The methods available for quantifying gene expression depend on a range of factors including the organism of interest, tissue availability, and the required spatial resolution. In smaller species such as mice, where specimens are more readily available, gene expression can be measured using in situ hybridization (Lein et al., 2007) where the transcriptional activity of each gene is measured in separate tissue samples at a cellular resolution. Tissue availability in humans is very limited, so bulk-tissue microarray (Schulze \& Downward, 2001) remains the most accessible method for high-throughput spatial transcriptomics in humans (Hawrylycz et al., 2012). With microarray, the expression levels of thousands of genes are quantified simultaneously using a single tissue sample. The Allen Human Brain Atlas (AHBA) provides the most anatomically comprehensive geneexpression data for the human brain, quantifying expression levels of more than 20,000 genes in 3702 different regions using microarray (Hawrylycz et al., 2012). Although atlases for developmental (Kang et al., 2011) and human-specific spatiotemporal gene-expression patterns (Sousa et al., 2017) are also available, the spatial coverage of these atlases is much sparser compared to AHBA, extending across only 16 brain regions [for an overview of different gene expression atlases see (Keil et al., 2018)]. The AHBA therefore represents the most readily accessible resource for linking measures of gene expression to a given brain-wide IDP.

Several considerations about the AHBA must be borne in mind. First, the atlas comprises data from only six individuals, precluding an opportunity to study in detail individual variability in regional gene expression. While it appears that expression differences are greater across regions than between people (Hawrylycz et al., 2015), the full extent and functional significance of inter-individual variation in gene expression remains unclear. Second, all measures are derived from adult brains, with donors ranging in age from 24 to 57 years; variations in expression may therefore be related to the myriad endogenous and exogeneous factors that can influence transcriptuonal activity (Kanherkar et al., 2014). While many genes show neotenous patterns of expression (Goyal et al., 2014), many others show marked changes in transcriptional activity across the lifespan (Berchtold et al., 2008; Işıldak et al., 2020). These changes can be tracked for some brain regions through developmental gene-expression atlases (Kang et al., 2011; Miller et al., 2014), but our understanding of regional differences in the transcriptional activity of different genes remains incomplete. Third, as gene expression in the AHBA is assayed using bulk tissue 
microarray, regional differences in gene expression could reflect variations in the cellular, functional, or anatomical composition of that region. Single-cell transcriptomics offers a way of disentangling these contributions, but the anatomical coverage of these atlases remains limited in comparison (Harris et al., 2018; Lake et al., 2016; Yao et al., 2021). Finally, the relationship between the transcriptional and translational activity of a gene is complex and influenced by multiple factors (Greenbaum et al., 2003; Gygi et al., 1999; Schwanhäusser et al., 2011). It is ultimately the latter that determines protein form and abundance and thus cellular function. Transcriptional atlases thus offer an indirect marker of more proximal molecular drivers of phenotypic variation.

Three main categories of analyses are performed in imaging transcriptomics (Figure 1a). One focuses on regional gene-expression patterns and aims to identify correlations between spatial variations in gene expression and anatomically defined IDPs across spatial locations (Romme et al., 2017; Seidlitz et al., 2020). A second category of analyses considers correlated gene expression (CGE), which quantifies the transcriptional similarity between pairs of regions across a set of genes. CGE can then be related to IDPs defined at the level of pairs of brain regions, such as measures of structural or functional connectivity (Arnatkeviciute, et al., 2021; Arnatkevičiūtè et al., 2018; Fulcher \& Fornito, 2016; Richiardi et al., 2015). A third analysis category examines gene coexpression, which quantifies the similarity of spatial expression profiles between pairs of genes, resulting in a gene $\times$ gene matrix. Statistical summaries of these gene $\times$ gene matrices, such as 'eigengene' measures of coherent subsets of coexpressed genes, have been computed and related to IDPs (Forest et al., 2017; Oldham et al., 2008). Note that in the literature, 'gene coexpression' has also been used to refer to analyses of CGE (Fulcher \& Fornito, 2016; Romero-Garcia et al., 2018).

An important consideration in any of these analyses is that both neuroimaging and transcriptional measures typically exhibit some degree spatial autocorrelation, meaning that values in different brain regions are not independent of each other. This spatial autocorrelation commonly takes the form of a decaying distance dependence between regional expression values, such that regions physically closer to each other have values that are more highly correlated than pairs of distant regions (Alexander-Bloch et al., 2013; Burt et al., 2018; Henderson \& Robinson, 2014; Lau et al., 2021; Roberts et al., 2016; Salvador et al., 2005). This dependence must be accounted for to ensure valid inference, and multiple approaches have been used (Alexander-Bloch et al., 2019; Arnatkeviciute, Fulcher, Oldham, et al., 2021; Burt et al., 2018, 2020; Fulcher \& Fornito, 2016; Selvaggi et al., 2021; Váša et al., 2018; Vértes et al., 2016; Wei et al., 2021). A comprehensive comparison of the efficacy of some of these approaches is provided by Markello and Misic (2020). 


\section{a}
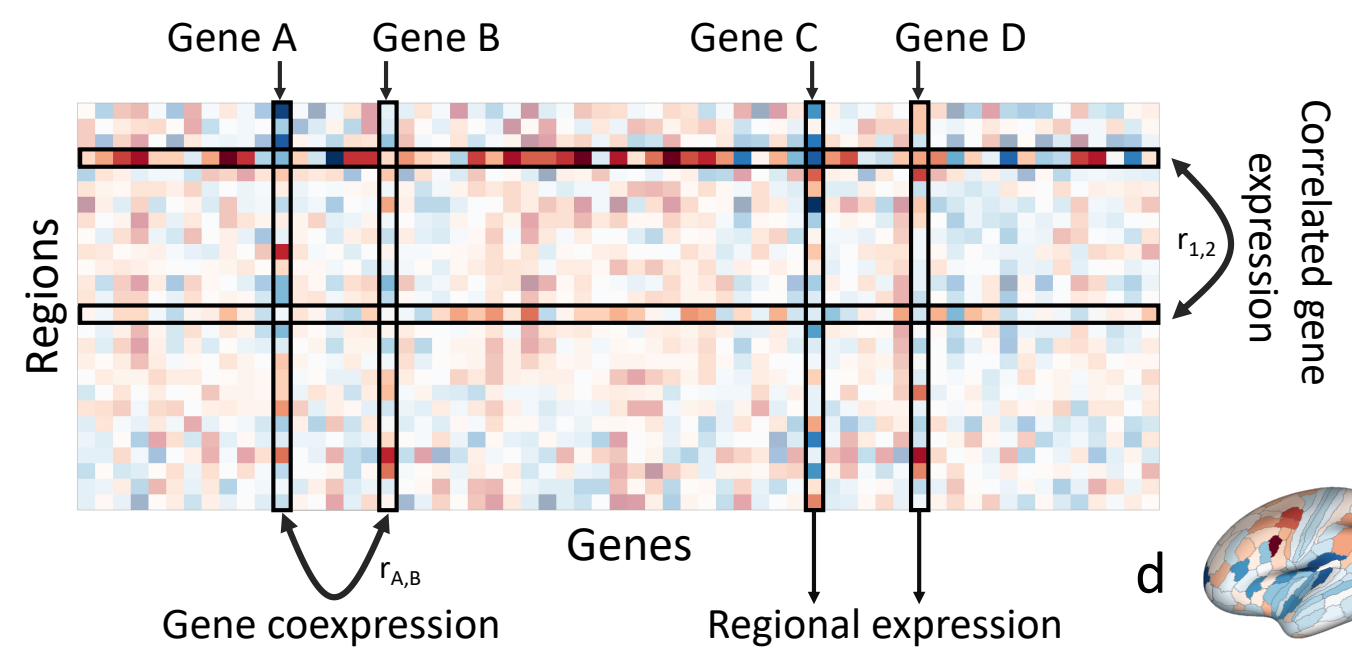

b
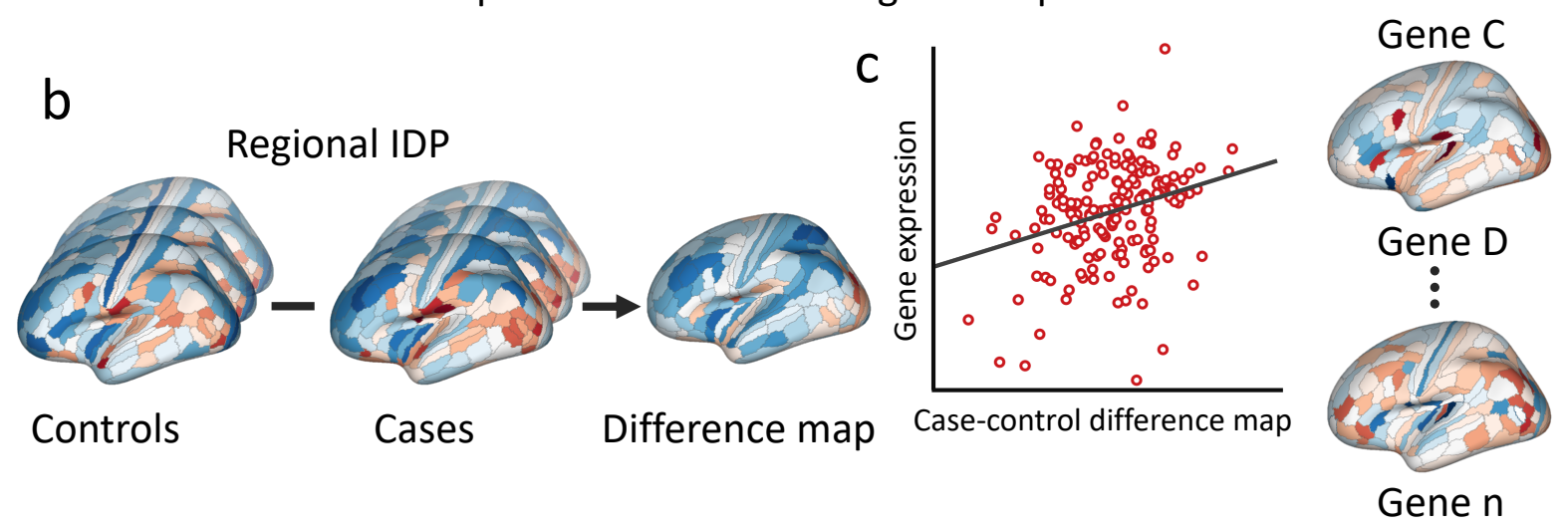

Figure 1 Approaches for relating gene expression to neuroimaging data. a) Transcriptional atlas data can be collated into a region $x$ gene matrix, from which different estimates of gene expression can be quantified. In this example, the regional expression profile of any given gene, indicating the spatial patterning of the gene's transcriptional activity, corresponds to a single column of the matrix. A given region's expression profile across genes corresponds to a row of the matrix. Correlated gene expression (CGE) is therefore calculated by correlating pairs of rows (resulting in region $\mathrm{x}$ region similarity matrix), while gene coexpression is calculated by correlating pairs of columns (resulting in gene $\mathrm{x}$ gene similarity matrix). b) When applied to brain disorders, spatial maps of a given IDP measures in cases and controls are compared to yield some kind of difference map. This difference map is then correlated (c) with the spatial maps of each gene (d) in a hypothesis- or data-driven method. Genes associated with high spatial correlations to the difference map represent transcriptional correlates of the IDP.

Imaging transcriptomics has been most commonly deployed in clinical contexts to investigate associations at the level of brain regions. More specifically, these analyses involve comparing a spatial map that quantifies casecontrol differences in a given IDP to the spatial expression pattern of each gene in either a hypothesis-driven or data-driven way (Figure 1b). Hypothesis-driven analyses typically focus on specific sets of genes identified $a$ priori whereas data-driven approaches aim to identify patterns across thousands of genes, which involves scoring each gene based on its association with a given IDP, either using mass univariate, gene-specific analyses, or multivariate approaches that relate IDPs to linear combinations of genes (Fulcher \& Fornito, 2016; Gao et al., 2020; Hansen et al., 2021; Richiardi et al., 2015; Seidlitz et al., 2020; Vértes et al., 2016; Whitaker et al., 2016). Based on experimental and theoretical evidence, genes have been grouped according to their biological and molecular functions, making it possible to test for the enrichment or over-representation of certain classes of genes using established annotation systems such as the Gene Ontology (GO) (Ashburner et al., 2000) or the Kyoto Encyclopedia of Genes and Genomes (KEGG) (Kanehisa \& Goto, 2000) through Gene Category Enrichment Analyses (GCEA). A range of statistical methods have been developed to accommodate different implementations of these analyses. For instance, when continuous gene scores are used GCEA tests whether a summary score for 
each category is higher than expected given some null distribution (Subramanian et al., 2005). Over-representation analysis (ORA), on the other hand, is used for thresholded lists of genes, where the purpose of the analysis is to determine if there are any gene sets that are statistically over-represented in that list compared to chance. Appropriate null models for such analyses are an active area of development (Burt et al., 2020; Fulcher et al., 2021; Wei et al., 2021). In a recent study, Fulcher et al. (2021) showed that standard null models can dramatically inflate false positive rates across $\mathrm{GO}$ categories. We will discuss some of these issues in more detail below, but the caveats are important to keep in mind when interpreting the findings presented in the literature. A further complication is that the gene expression data must be processed before they can be related to imaging measures. This processing involves multiple steps, each of which requires choices between different processing options (Arnatkeviciute et al., 2019) that can have a substantial effect on the final results (Markello et al., 2021; Selvaggi et al., 2021) and care should be taken when thinking about data processing. The recently developed abagen toolbox can assist in running consistent workflows (Markello, 2021).

\section{Neurodevelopment and its disorders}

Age-related changes in cortical structure and function are associated with normal brain development (Giedd \& Rapoport, 2010; Gilmore et al., 2018; Knickmeyer et al., 2008), with cortical thinning being regarded as a morphological hallmark of cortical maturation (Amlien et al., 2016; Tamnes et al., 2017). Brain-wide changes in cortical thickness, mostly involving cortical thinning, are also associated with a range of psychiatric disorders (Khundrakpam et al., 2017; Narr et al., 2009; Niu et al., 2017; Suh et al., 2019; van Haren et al., 2011). Cortical thickness differences observed in many neurodevelopmental disorders, including schizophrenia, are thus often thought to arise from altered trajectories of brain maturation (Gogtay et al., 2011; Häfner et al., 1994). These cortical thickness changes may be driven by changes to neuronal and/or synaptic size and/or density or the myelination of fibers penetrating the cortical mantle (Natu et al., 2019).

To shed light on the molecular correlates of brain changes that occur in both normal and aberrant neurodevelopment, imaging transcriptomic studies have used the expression profiles of specific cell-type marker genes to identify cellular corelates of these IDPs. The expression levels of cell-specific marker genes have been shown to act as indirect proxies for the relative abundance and/or function of each cell type (Mancarci et al., 2017; Zeisel et al., 2015). A correlation between the cell-type marker and the IDP is regarded as implicating that cell type as being linked to the phenotype, but such correlational relationships should be interpreted with some caution. Indeed, while the relationship between gene expression and cell abundance for some cell types is very strong, not all cell-type markers demonstrate the same degree of correspondence (Fulcher, 2019).

One analysis of cell-type markers found that regional variations of the magnetization transfer ratio (MTR), which is commonly used to index myelin content (Schmierer et al., 2004), are associated with CA1 pyramidal and ependymal cells, but not myelination, in mid-adolescence (mean age $=14$ years) (Patel et al., 2019). Considering that the CA1 pyramidal gene-set is enriched in genes that are also related to dendritic organization, the authors suggest that variations in MTR across the brain could be related to regional differences in dendritic arborization. Subsequent longitudinal changes in MTR from mid-to-late adolescence, however, were related to the expression 
of oligodendrocyte cell markers and genes involved in myelination (Patel et al., 2019). Similar associations implicating oligodendrocyte and neurotransmission-related genes were found in relation to changes in both MTR and cortical thickness between 14 and 24 years through the partial least squares (PLS) regression (Whitaker et al., 2016). The fact that a single PLS component demonstrated associations with both measures implies that cortical myelination and thinning may act together as mechanisms of cortical consolidation that are at least in part driven by genes with correlated expression patterns. Other studies, conducted both cross-sectionally and longitudinally, indicate that transcriptional markers of astrocytes, microglia, and CA1 pyramidal cells are linked to thicker cortex in young individuals and enhanced cortical thinning later in life, as shown in Figure 2a (Shin et al., 2018; VidalPineiro et al., 2020). This suggests that changes in cortical thickness across the lifespan are closely tied to the expression levels of these genes. Dendritic spine- and dendrite-related genes show associations with cortical thinning in late childhood (9-12 years) and late adolescence (17-19 years), whereas myelin-specific genes were related to cortical thinning in mid-adolescence (12-15 years) (Parker et al., 2020). Moreover, the directionality of the relationship changed over time such that in early maturation, regions with higher expression of those genes showed greater cortical thinning; in later stages, greater cortical thinning was observed in regions with lower expression. Multivariate analyses have further indicated that accelerated cortical thinning during the period from 3 to 21 years is associated with increased expression of gene markers for inhibitory and excitatory neurons, in addition to genes linked to synaptic remodeling and neurodevelopment, mood, and addiction disorders (Ball et al., 2020). The spatial expression patterns across different gene groups can explain a large proportion of variation in average cortical thickness across regions, accounting for up to $70 \%$ early in life (Shin et al., 2018). 
a

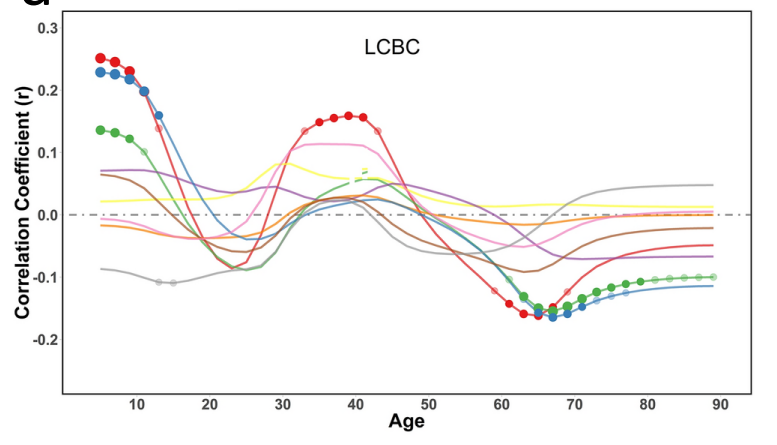

b

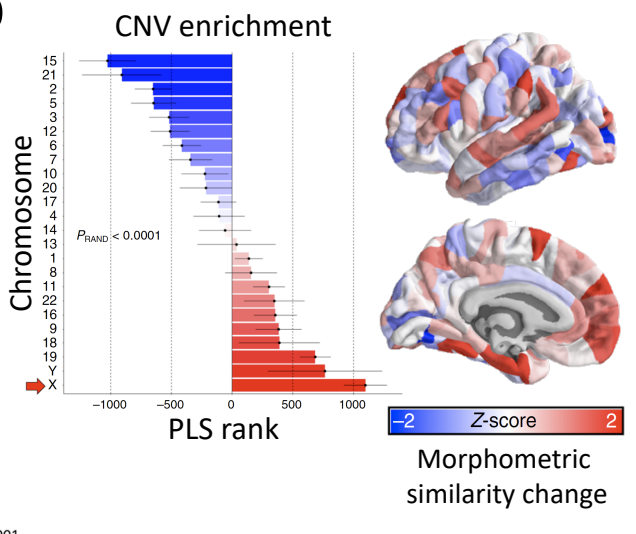

.0001
C

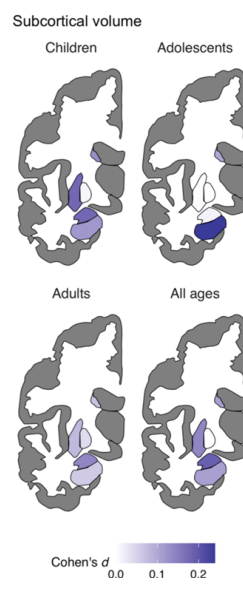

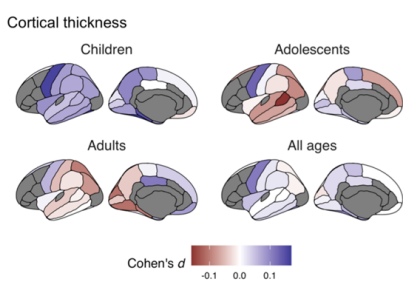

Surface area

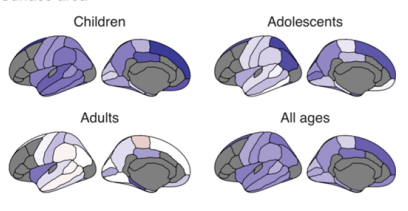

Cohen's $d$ t

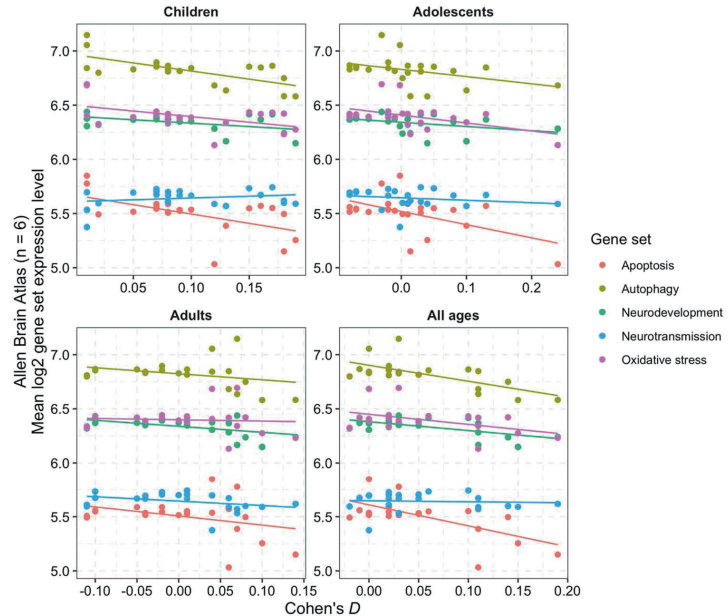

Figure 2. Transcriptional correlates of neurodevelopment and neurodevelopmental disorders. a) The relationship between cortical thinning profile (i.e., the degree of cortical thinning per year) throughout life and gene expression in each of 9 cell types. Both in early and late life, significant associations (indicated by circles) were identified for astrocyte, microglia and CA1 pyramidal cell markers. b) Regional morphometric similarity change observed in Turner syndrome (characterized by the loss of the X-chromosome) and chromosome ranking from a PLS analysis, based on the median rank of gene loadings on a PLS-derived latent variable linking gene expression with regional morphometric similarity change. The chromosomal gene set for the $\mathrm{X}$ chromosome shows the lowest rank, which is consistent with the chromosomal deletion known to cause the disorder. c) Correspondence between brain changes in ADHD and gene expression. Left: differences in cortical thickness, surface area and subcortical volumes in ADHD as identified by the ENIGMA Consortium, where larger positive Cohen's $\mathrm{d}$ correspond to decreases in a particular measure in ADHD patients vs controls. Right: the relationship between regional brain volumes and the expression of genes involved in apoptosis, autophagy, neurodevelopment, neurotransmission and oxidative stress-related genes. Apoptosis, autophagy and neurodevelopment-related genes demonstrate significant negative associations such that higher expression of those genes is associated with reductions in brain volume in ADHD patients. Panel a adapted with permission from (Vidal-Pineiro et al., 2020). Panel b adapted with permission from (Seidlitz et al., 2020). Panel c adapted with permission from (Hess et al., 2020).

A recent study of different neurogenetic conditions has shown the potential power of imaging transcriptomics for identifying pathophysiologically relevant links between IDPs and spatial gene expression patterns. The conditions considered are caused by well-localized genomic copy number variations (CNVs), including Turner syndrome, Velocardiofacial syndrome, Down syndrome, Wilms Tumor-Aniridia syndrome, and sex chromosome aneuploidies (XXX, XXY, XYY, XXYY) (Seidlitz et al., 2020). The distinct gene sets defining each of these conditions are known, leading to clear hypotheses about which specific genes should show correlated expression patterns with macroscale imaging measures of brain pathology. In this particular analysis, the authors focused on the average morphometric similarity (MS) of each region to all other brain areas, with MS defined as inter-regional correlations across multiple imaging measures of regional neuroanatomy and microstructure (Seidlitz et al., 2020). The analysis revealed that regional differences in MS between cases and controls were related to the specific spatial expression of causal genes for each disorder (Figure 2b). Similar approaches have been applied to 
neurodevelopmental disorders with more complex genetics, such as attention-deficit hyperactivity disorder (ADHD) and autism spectrum disorder (ASD). Measures of ADHD-associated decreases in subcortical volume, cortical thickness, and surface area, estimated in two large samples through analysis of ENIGMA Consortium data, were consistently associated with genes implicated in apoptosis and autophagy pathways, such that higher expression of those genes corresponded to stronger decreases in these brain measures (Hess et al., 2018, 2020)(Figure 2c). Moreover, cell deconvolution analysis, which aims to infer cell-type abundance from geneexpression levels, identified that smaller regions had elevated levels of astrocytes and oligodendrocyte progenitor cells, implying a compensatory response of glial cells (Hess et al., 2020). In ASD, two separate studies provide convergent evidence that changes in both cortical thickness (Romero-Garcia et al., 2019) and regional volumes (Xie et al., 2020) are related to the expression of genes that are transcriptionally downregulated in ASD postmortem cortical tissue. Additionally, the regional distribution of cortical-thickness alterations observed in ASD was also associated with synaptic transmission genes (Romero-Garcia et al., 2019) whereas changes in regional volumes were associated with nervous system and ion transport-related genes (Xie et al., 2020).

Together, this work indicates that developmental alterations in cortical properties are associated with the expression of cell-type marker genes, supporting a link between cellular properties and macroscale phenotypes measured using non-invasive brain imaging. In particular, the analyses of neurogenetic conditions with known genetic origins serve as evidence for the utility of imaging transcriptomics for investigating the genetic correlates of disorder-associated changes.

\section{Psychiatric disorders}

Cell-type marker gene analyses have also been applied to study disorders with onset later in life. Using data from the ENIGMA consortium, one study found that the spatial patterning of cortical thickness differences between cases and controls for 6 psychiatric disorders, including ADHD, ASD, major depression, OCD, bipolar disorder, and schizophrenia, is consistently related to the regional expression of transcriptional markers for CA1 pyramidal cells, astrocytes, and microglia (Patel, Yash et al., 2021) (Figure 3a). These same cell-specific groups of genes have been consistently linked to cortical thickness across the lifespan (Shin et al., 2018; Vidal-Pineiro et al., 2020), pointing to shared genetic mechanisms linking neurodevelopmental and adult psychiatric disorders. 
a

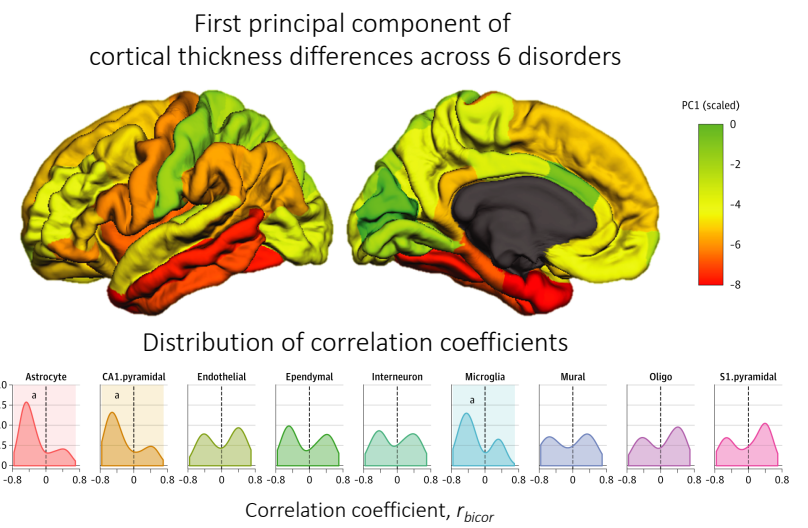

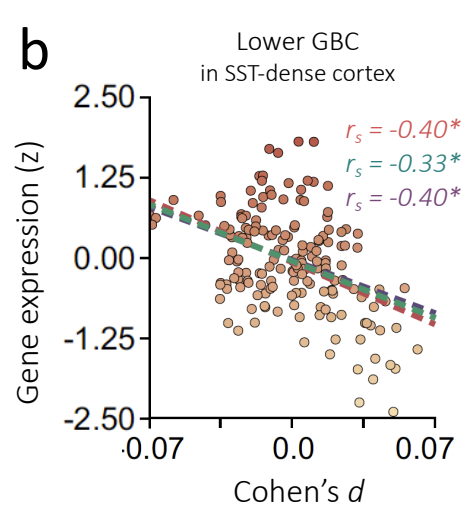

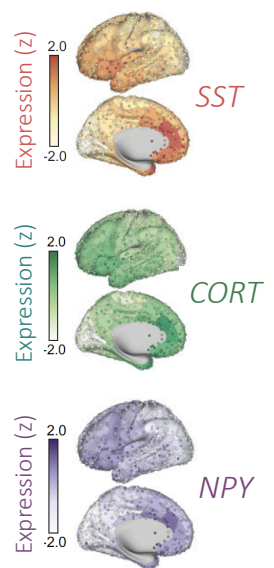

C

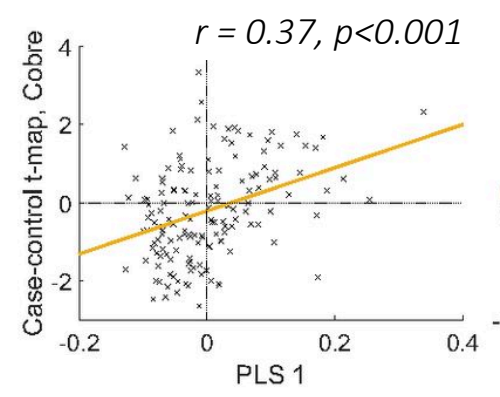

Weighted gene expression map (PLS1)
Mean case-control t-statistic map

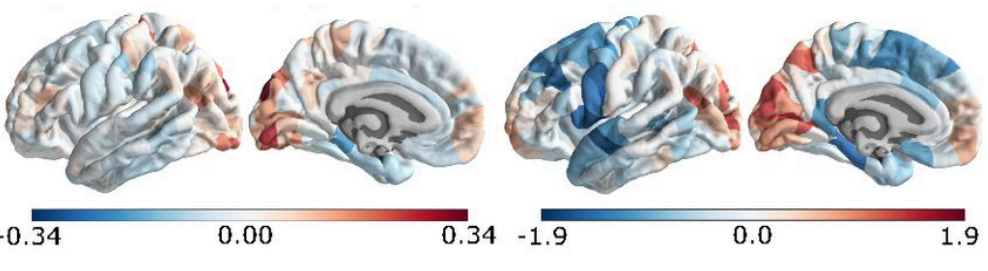

Figure 3 Transcriptional correlates of brain changes in neuropsychiatric disorders. a) Principal component analysis of cortical thickness changes across six psychiatric disorders. The first principal component (PC1) is significantly correlated with spatial expression profiles of astrocyte, microglia, and CA1 pyramidal cells. Negative PC1 values indicate greater differences in cortical thickness between cases and controls shared across six disorders. b) Associations between the cortical gene expression of somatostatin (SST) interneurons [SST, cortistatin (CORT), and neuropeptide Y (NPY)] and reduced global brain connectivity (GBC) in depression. The scatter plot represents the relationship for SST genes, regression lines represent relationships for all three gene markers. c) Gene expression profiles are associated with morphometric similarity differences between psychosis cases and controls. Cortical maps represent regional PLS1 scores (right) and case-control differences in morphometric similarity. Panel a adapted with permission from (Patel, Yash et al., 2021). Panel b adapter with permission from (Anderson, Collins, Kong, et al., 2020). Panel c adapted with permission from (Morgan et al., 2019).

More specific investigations into individual psychiatric disorders have identified the involvement of neurobiologically relevant and disorder-associated genes. For example, half of the genes implicated in schizophrenia through GWAS were correlated to deviations in regional grey-matter volume between cases and controls (Ji et al., 2021). The same set of genes was also enriched for chemical synaptic transmission, central nervous system development, and cell projection, categories that are linked to both connectivity and developmental processes. Interneuron-related dysfunction has been regarded as one of the core features of psychopathology in schizophrenia (Lewis et al., 2012). In line with this hypothesis, polygenic risk for schizophrenia has been shown to be significantly enriched for genes demonstrating spatial coexpression to PVALB genes, one of the core markers for interneurons that demonstrates a characteristic spatial variability correlated with variations in fMRI signal amplitude across the brain (Anderson, et al., 2020). Extending the link to nonclinical populations, schizotypy-related regional MTR variations show associations with genes involved in neuronal affiliation, astrocytes, and microglia, that are transcriptionally dysregulated in post-mortem schizophrenia studies (Romero-Garcia et al., 2020). These results indicate that genes involved in neurodevelopment and synaptic function are related to macroscale brain changes in schizophrenia. 
Other work has focused on various aspects of brain connectivity, in line with the dysconnectivity hypothesis of schizophrenia (Fornito et al., 2012; Stephan et al., 2009). Connectivity can been assessed indirectly, using MS networks (Seidlitz et al., 2018) or structural covariance networks, which quantify inter-regional coupling of morphometric measures such as grey-matter volume or cortical thickness (Alexander-Bloch et al., 2013; Gong et al., 2012; Goulas et al., 2017), or more directly using diffusion MRI (Heuvel et al., 2010; Zalesky et al., 2011, see also (Fornito et al., 2012)). Regional mean MS differences between cases and controls have been linked to the expression of genes regulating synaptic signaling, nervous system development and the adenylate cyclasemodulating G-protein coupled receptor signaling pathway that is responsible for changes in the concentration of cyclic AMP, a molecule used in intracellular signal transduction (Morgan et al., 2019) (Figure 3c). Moreover, genes that were overexpressed in regions with reduced MS were significantly upregulated in post-mortem studies of schizophrenia, suggesting a tight coupling between ex vivo measures and the transcriptional correlates of IDPs measured in vivo. Regional white-matter dysconnectivity in schizophrenia, quantified with diffusion MRI, was significantly correlated with the spatial profile of schizophrenia-related genes identified through the same GWAS (Romme et al., 2017), providing a direct link between structural risk variants, gene expression, and macroscale alterations of connectivity in the disorder. Notably, connectivity changes in bipolar disorder were associated with the expression of risk genes implicated in bipolar disorder, but not schizophrenia, suggesting some level of diagnostic specificity to these associations. There is also some evidence that these genes are specifically linked to diffusion MRI IDPs, given that they have shown only weak associations with other measures (Liu et al., 2019).

Studies of Major Depressive Disorder (MDD) have consistently identified links between IDPs and the spatial expression pattern of genes that are also transcriptionally dysregulated in post-mortem studies. Li et al. (2021) used multivariate analysis to identify linear combinations of almost 3000 genes enriched in synapse-related terms and other neurobiologically relevant categories that were related to regional case-control differences in MS. Thirty-four of those genes were also transcriptionally dysregulated in post-mortem tissues, mirroring previous findings (Anderson, Collins, Kong, et al., 2020; Romero-Garcia et al., 2020). These associations were specific to depression and not evident for genes dysregulated in other psychiatric disorders (Li et al., 2021). Functional MRI analysis has revealed that temporal fluctuations in regional signal homogeneity are linked to the expression of several neurobiological gene categories that include synaptic signaling, metabolism, central nervous system development, and neurodegenerative disease (Xue et al., 2020). In a separate study, regional changes in anatomical and functional properties of the brain linked to a history of depression and negative affect were investigated across three large-scale neuroimaging cohorts (Anderson, Collins, Kong, et al., 2020). Depressionrelated brain-wide decreases in resting state functional amplitude, mean regional strength of functional connectivity and cortical thickness were correlated with gene markers for somatostatin interneurons, in line with the hypothesis that the dysfunction of cortical somatostatin interneurons plays a central role in the onset of depression (Figure 3b). Moreover, these depression-related changes in anatomical and functional maps were correlated with the spatial expression pattern of genes down-regulated in post-mortem specimens from patients. Such associations were not found for other psychiatric disorders, again supporting the specificity of these links between imaging and transcriptional measures (Anderson, Collins, Kong, et al., 2020). 
In summary, across different psychiatric disorders and imaging modalities, genes that are spatially correlated with disorder-related changes in brain structure or function tend to overlap with genes that are transcriptionally dysregulated in post-mortem samples derived from clinical populations, and/or genes implicated in disease risk by large-scale GWAS. While there is evidence of diagnostic specificity in some of these associations, some transcriptional correlates are consistent across disorders and may reflect common genetic influences on disease risk (Patel, Yash et al., 2021).

\section{Neurodegeneration and associated disorders}

Neurodegenerative diseases, such as Huntington's disease (HD), Alzheimer's disease (AD) and Parkinson's disease (PD), are associated with characteristic neurodegenerative patterns (Ballatore et al., 2007; Johnson et al., 2021; Seeley, 2017) that are linked to the accumulation of particular neurochemical agents such as amyloid $\beta$ protein $(\mathrm{A} \beta)$ and tau in $\mathrm{AD}$, and $\alpha$-synuclein in PD (Ballatore et al., 2007). Transcriptional atlas data can be used to identify the molecular correlates of regional vulnerability to disorder-specific neurodegeneration and help understand how the disease spreads across the brain. For instance, Huntington's disease is caused by a mutation in the single gene, HTT (Myers, 2004), but imaging transcriptomics has begun to shed light on other potential molecular pathways related to brain-wide dysfunction in the disorder, given evidence that degeneration of corticostriatal and inter-hemispheric connectivity in pre-manifest HD has been associated with the spatial expression patterns of genes related to chemical synaptic transmission and cell projections, with the genes most strongly linked to the IDPs also being transcriptionally dysregulated in post-mortem studies of patients (McColgan et al., 2018).

In comparison to $\mathrm{HD}$, the genetic mechanisms underlying risk for Alzheimer's disease are more complex (Jansen et al., 2019). Cell-type specific marker analyses indicate that decreases in cortical thickness in AD patients compared to healthy subjects are linked to the expression of the same cell-specific gene groups that are involved in both age-related changes in cortical thickness and psychiatric disorders; namely CA1 pyramidal cells, microglia, and astrocytes (Figure 4a). Moreover, genes that were co-expressed with microglial genes were significantly enriched for $\mathrm{AD}$ risk, providing a direct link to the aetiology of the disease and implying a critical role for neuroinflammation (Vidal-Pineiro et al., 2020). One study first identified spatial clusters of voxels that showed reduced volume in people carrying a higher number of AD risk alleles (Roshchupkin et al., 2016). These reductions were then investigated in relation to the expression patterns of genes that are in close proximity to $\mathrm{AD}$ risk loci resulting in a set of 216 genes. Although only five of those genes showed significant associations with the volumetric reductions, three of them (MEF2C,CLU and SLC24A4) were previously identified as AD risk genes, linking the spatial patterning of gene expression back to structural risk variants.

Type 2 diabetes (T2D) is associated with increased risk for AD (Lu et al., 2009). Nugent et.al. (2020) investigated the expression of genes that are close to $46 \mathrm{~T} 2 \mathrm{D}$ risk SNPs and found that the spatial expression patterns of just 5 of these genes could explain more than $70 \%$ of variance in regional glucose metabolism uptake in both healthy and probable $\mathrm{AD}$ groups, thus demonstrating a link between risk factors for T2D and glucose metabolism in both normal aging and AD. Similar findings were demonstrated in PD, where regional expression of only 17 genes that were previously implicated in the disease explained $42 \%$ of variance in regional disease-related atrophy patterns 
(Freeze et al., 2018). Regional gene expression could also explain $20 \%$ of variance in quantitative susceptibility mapping measures, which index iron deposition (Thomas et al., 2021) (Figure 4b). Genes associated with iron deposition were transcriptionally dysregulated in post-mortem specimens of patients with PD, PD with dementia and dementia with Lewy bodies, pointing to common mechanisms that drive regional susceptibility to neurodegeneration across diagnostic categories.

Other hypothesis-driven work has supported the general involvement of the tau protein in different neurodegenerative conditions. Regional expression of the MAPT gene, which codes for the tau protein is associated with the severity of neurodegeneration in Alzheimer's disease (Grothe et al., 2018) and has been linked to reduced functional connectivity in patients with Parkinson's disease (Rittman et al., 2016). At the same time, the expression of $A P P$, a gene that encodes amyloid precursor protein, was associated with regional amyloid burden, but not neurodegeneration (Grothe et al., 2018). Together the results from these two studies suggest that the spread of neurodegeneration in both $\mathrm{AD}$ and $\mathrm{PD}$ is primarily mediated by tau pathology.

Multiple lines of evidence suggest that neurodegeneration across disorders originates in a relatively small number of susceptible regions and then propagates along axonal pathways (Brettschneider et al., 2015; Desplats et al., 2009; Fornito et al., 2015; Jucker \& Walker, 2018). These spreading processes can be modelled mathematically using various diffusion models simulated on an underlying brain-network architecture (Cornblath et al., 2021; Pandya et al., 2019; Raj et al., 2012). One such model was used to predict the pathological seed regions and pattern of disease spread in PD and then test the assumption that transcriptional profiles of 67 PD risk genes derived from a GWAS are associated with disease origination and progression (Freeze et al., 2019). The results indicated that the expression patterns of those genes are related to the likelihood of a region being identified as the initiation site for the pathology and are related to early disease spread, but not the resulting regional atrophy pattern. More specifically, the expression of several immune-related (HLA-DQA1, HLA-DRB6, IL1R2) and lysosomal (GBA, TMEM175) PD risk genes was most strongly associated with seed regions consistent with a causal role of lysosomal dysfunction and neuroinflammation in PD pathogenesis (Freeze et al., 2019). Another study proposed an agent-based $S-I-R$ model where the agents are individual proteins that spread to affect different regions in the network, leading to regions having the status of either susceptible ( $S$, yet to be infected), infected ( $I$, capable of transmitting the infection), or removed ( $R$, no longer active in disease spread), as shown in Figure 4c (Zheng et al., 2019). Incorporating the regional expression of $S N C A$ and $G B A$ genes, which are involved in the synthesis and clearance of $\alpha$-synuclein respectively, into the model improved the correspondence between modelled and empirically-observed atrophy patterns in PD (Zheng et al., 2019). Extending this agent-based model to include a factor responsible for the transmission probability of pathological agents, by incorporating the expression patterns of the LRRK2 gene implicated in the development of PD through the transmembrane transport, further improved model accuracy, supporting a role of LRRK2 in modulating the propagation of misfolded proteins (Yan et al., 2020). Transcriptional atlas data thus provide a principled way of constraining and parameterizing models of dynamical processes in both health and disease (see also Deco et al., 2021). 


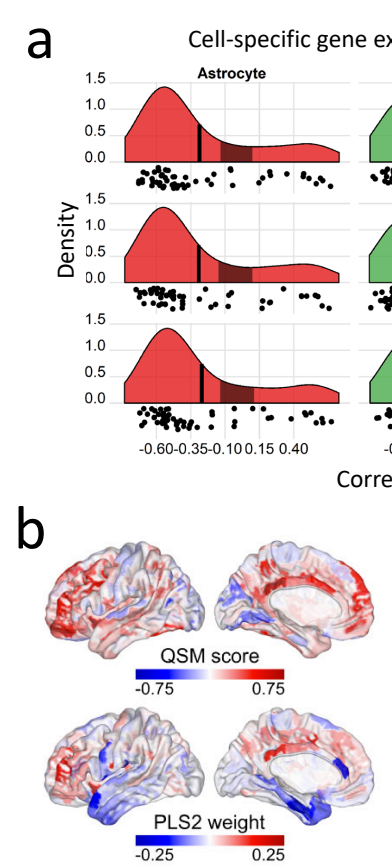

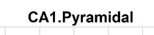

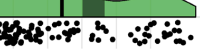
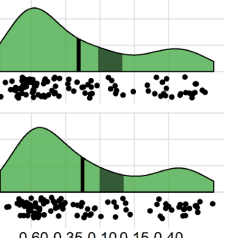

$0.00-0350.100 .150 .40$

lation coefficient $(r)$

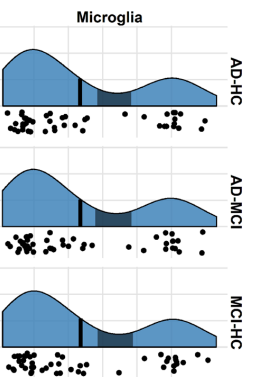
$-0.60-0.35-0.100 .150 .40$

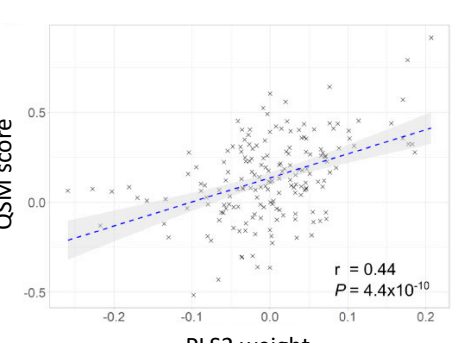

PLS2 weight

C Modeling neurodegenerative disease propagation

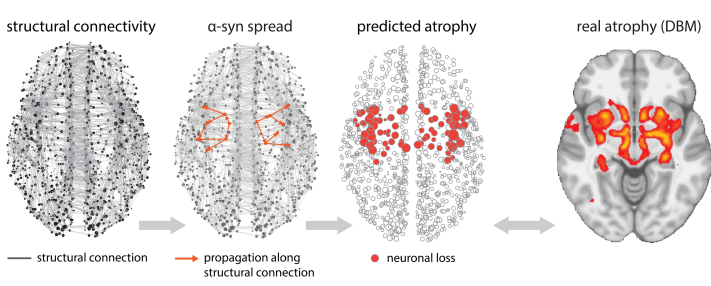

empirical atrophy
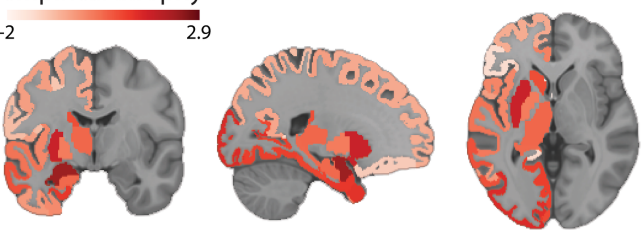

simulated atrophy
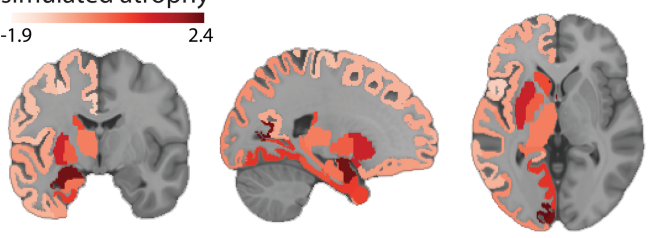

Figure 4 Gene expression is related to neurodegeneration and neurodegenerative disease spread. a) Cell-specific marker association with cortical thinning in AD. Correlation distributions quantifying the relationship between cell-specific gene expression profiles for CA1 pyramidal, microglia and astrocyte cell types and cortical thickness reductions in $\mathrm{AD}$ (AD vs healthy controls; AD vs Mild Cognitive Impairment (MCI); MCI vs AD). Vertical axis denotes estimated probability density for the correlation coefficients. Vertical black line denotes the average correlation coefficient across all genes; shaded grey box indicates the $95 \%$ limits of the empirical null distribution. b) Gene expression is associated with cortical iron decomposition, quantified using quantitative susceptibility mapping (QSM), in Parkinson's disease. Cortical maps represent QSM scores and regional linearly weighted sum of gene expression scores defined by the PLS2. c) Schematic representation of pathology spread across the brain: misfolded $\alpha$-synuclein propagates via structural connections; simulated neuronal loss (atrophy) is compared against empirical atrophy, estimated from Parkinson's disease patients. Simulated and empirical atrophy patterns show a high level of spatial correspondence (Spearman correlation, $r=0.63, p=2 \times 10^{-5}$ ). Panel a adapted with permission from (Vidal-Pineiro et al., 2020). Panel b adapted with permission from (Thomas et al., 2021). Panel c adapted with permission from (Zheng et al., 2019).

Together, studies of neurodegeneration highlight the role of cell-specific and disorder-related genes in regional vulnerability to neurodegeneration. Specifically, the involvement of CA1 pyramidal cells, microglia, and astrocytes is evident across the lifespan, suggesting common mechanisms associated with healthy development, ageing, and clinical neurodegeneration. Differences in regional vulnerability to neurodegeneration and subsequent spread of the disease are also linked to the expression patterns of genes involved in disease pathology. The integration of transcriptional atlas data with models of network dynamics appears to be a particularly fruitful avenue for testing different hypotheses about disease evolution.

\section{Challenges for the field}

The findings considered here highlight the potential of imaging transcriptomics to identify the molecular correlates of clinically relevant IDPs. However, the field is nascent and several methodological challenges must be overcome to ensure the robustness of the findings. One such challenge is that the transcriptional atlas data often require a degree of processing before they are ready for analysis. The processing involves several steps, including mapping of tissue samples to regions of interest defined using a specified parcellation, selecting representative gene probes to quantify the expression of a gene, and accounting for gene-expression differences between donor 
brains. Some of these steps entail choices that can alter resulting spatial expression maps and affect the final results (Arnatkeviciute et al., 2019; R. D. Markello et al., 2021; Selvaggi et al., 2021). Just as variations in the processing of neuroimaging data can affect final outcomes (Aquino et al., 2020; Botvinik-Nezer et al., 2020; Ciric et al., 2017; Oldham et al., 2020; Parkes et al., 2018), different choices in the processing of expression data can influence one's findings. Some of these choices have been investigated in detail, leading to the proposal of recommended workflows and open-source toolboxes (Arnatkeviciute et al., 2019; Markello et al., 2021).

A second challenge is related to the intrinsic spatial autocorrelation of both gene expression and neuroimaging data. This autocorrelation is such that regions that are in close proximity to each other often exhibit more similar gene expression profiles and IDP values (Arnatkeviciute et al., 2019; Burt et al., 2018; Lau et al., 2021; Roberts et al., 2016; Salvador et al., 2005). Spatially autocorrelated gene-expression patterns are prominent across species, including in mouse (Fulcher \& Fornito, 2016; Lau et al., 2021) and human (Arnatkeviciute et al., 2019; Krienen et al., 2016; Pantazatos \& Li, 2017; Richiardi et al., 2015, 2017), with gene-expression correlations decaying approximately exponentially with separation distance. Moreover, the correlation length scales with brain size across mouse development (Lau et al., 2021). The spatial autocorrelation of gene-expression patterns results in non-independent spatial samples, and thus requires more careful statistical analysis than applying traditional statistical methods that assume independence. Accordingly, studies that have used parametric statistical methods or randomization approaches that do not preserve the intrinsic spatial autocorrelation of the data, will yield lenient estimates of statistical significance and inflate the false-positive rates (Markello \& Misic, 2020). Alternative null models, such as premutation-based procedures that preserve the spatial structure of the data (A. F. AlexanderBloch et al., 2019; Váša et al., 2018), model-based techniques that generate surrogate data that preserve spatial autocorrelation structure (Burt et al., 2018, 2020), or regression-based measures that account for distance effects (Fulcher \& Fornito, 2016), are required for valid significance testing between spatial maps. Notably, the performance of different spatially constrained randomization techniques can depend on the research context (Markello \& Misic, 2020).

A third challenge relates to characterizing the specificity of gene effects in hypothesis-driven analyses. Are the observed effects for selected genes exclusive or could other gene sets show similar associations with IDPs? Gene specificity should be examined relative to randomly selected subsets of random genes of the same size as the hypothesized set. One recent study has demonstrated that even among the associations (identified through linear regression) that survive the spatial null significance testing, $42 \%$ are not specific to selected genes but can be found for a wide range of random genes, and only $5 \%$ of associations could surpass both spatial and random gene nulls, suggesting that gene and spatial specificity should be evaluated in tandem for appropriate significance testing (Wei et al., 2021). Moreover, other properties of spatial gene expression, such as their tissue specificity and the strength of coexpression between genes in a tested set, need to be considered in order to provide a null distribution that is adequate for evaluating the specificity of the relationships between IDPs and brain-specific variations in gene expression (Fulcher et al., 2021; Wei et al., 2021).

A fourth challenge concerns statistical inference in GCEA. Traditional GCEA workflows were developed for the investigation of individual tissue samples or structural DNA variation and were not designed to deal with spatially embedded atlas data. The approaches have nonetheless been used in virtually all enrichment analyses in imaging 
transcriptomics studies thus far. Under the traditional workflow, the statistical significance of a gene category is computed with respect to a null distribution generated by randomizing gene-to-category assignments. Fulcher et al. (2021) showed that this approach, when used to test for enrichment of correlations with random brain-wide phenotypic maps, can lead to an average inflation in the false-positive rate across all GO categories exceeding 500-fold. The false-positive bias is largely driven by gene-gene coexpression within a category, such that categories containing genes with more consistent expression patterns are more susceptible to this bias. This effect is additionally modulated by gene-specific variations in spatial autocorrelation properties. These issues raise concerns regarding to the validity of many enrichment analyses that apply GCEA to transcriptional atlas data, considering that $\mathrm{GO}$ categories with the highest false-positive rates tend to be related to brain function and, as shown by Fulcher et al. (2021), are among the most frequently reported in the literature. One way to address this problem is to randomize the IDP rather than the gene-expression data. Depending on the hypothesis, it may be appropriate to randomize the IDP in a way that accounts for its intrinsic spatial autocorrelation [e.g., (Burt et al., 2020; Markello \& Misic, 2020)]. With this approach, the number of significantly enriched categories observed for several neural phenotypes measured in human and mouse dropped considerably when compared to the standard implementation; for example, 9 out of 14 GCEA analyses performed by Fulcher et al. (2021) yielded significantly enriched GO categories under the conventional null, whereas only one analysis revealed significant enrichment under a random phenotype null and none under a null using random spatially autocorrelated phenotypes null. These results highlight the importance of performing enrichment analyses with respect to carefully designed null models and indicate the need for caution when interpreting GCEA reports in imaging transcriptomics.

\section{Conclusions}

Imaging transcriptomics has been applied in diverse clinical settings across the lifespan. IDPs of neurodevelopmental conditions have been linked to gene groups involved in cell death and neuronal communication, or those known to play a causal role in the disorder. For disorders with later onset, specific transcriptional correlates of IDPs are related to transcriptionally dysregulated genes in clinical post-mortem samples and genes implicated in disease risk by GWAS. Transcriptional correlates of connectivity-related phenotypes show some evidence of disorder specificity whereas those related to cortical thickness may be disorder-general. In neurodegeneration, the expression of pathology-related genes for specific diseases is related to regional vulnerability and spread of the disease.

As the field develops, we anticipate that the refinement of existing methodologies will enable more robust and rigorous inference. Such methods, when coupled with increasingly more comprehensive and precise transcriptional atlas data, measured across more individuals and multiple points across the lifespan, will offer a powerful framework for identifying the molecular correlates of disease-related brain changes observed in vivo, and thus for linking microscale models of disease pathophysiology with macroscale measures of brain dysfunction. 


\section{Acknowledgements}

AF was supported by the National Health and Medical Research Council of Australia (IDs: 1146292 and 1197431) and Sylvia and Charles Viertel Charitable Foundation. MAB was supported by a National Health and Medical Research Council of Australia Senior Research Fellowship. 


\section{References}

Alexander-Bloch, A. F., Mathias, S. R., Fox, P. T., Olvera, R. L., Göring, H. H. H., Duggirala, R., Curran, J. E., Blangero, J., \& Glahn, D. C. (2019). Human Cortical Thickness Organized into Genetically-determined Communities across Spatial Resolutions. Cerebral Cortex (New York, NY), 29(1), 106-118.

https://doi.org/10.1093/cercor/bhx309

Alexander-Bloch, A. F., Vértes, P. E., Stidd, R., Lalonde, F., Clasen, L., Rapoport, J., Giedd, J., Bullmore, E. T., \& Gogtay, N. (2013). The anatomical distance of functional connections predicts brain network topology in health and schizophrenia. Cerebral Cortex (New York, N.Y.: 1991), 23(1), 127-138. https://doi.org/10.1093/cercor/bhr388

Alexander-Bloch, A., Giedd, J. N., \& Bullmore, E. (2013). Imaging structural co-variance between human brain regions. Nature Reviews Neuroscience, 14(5), 322-336. https://doi.org/10.1038/nrn3465

Amlien, I. K., Fjell, A. M., Tamnes, C. K., Grydeland, H., Krogsrud, S. K., Chaplin, T. A., Rosa, M. G. P., \& Walhovd, K. B. (2016). Organizing Principles of Human Cortical Development-Thickness and Area from 4 to 30 Years: Insights from Comparative Primate Neuroanatomy. Cerebral Cortex, 26(1), 257-267. https://doi.org/10.1093/cercor/bhu214

Anderson, K. M., Collins, M. A., Chin, R., Ge, T., Rosenberg, M. D., \& Holmes, A. J. (2020). Transcriptional and imaging-genetic association of cortical interneurons, brain function, and schizophrenia risk. Nature Communications, 11(1), 2889. https://doi.org/10.1038/s41467-020-16710-x

Anderson, K. M., Collins, M. A., Kong, R., Fang, K., Li, J., He, T., Chekroud, A. M., Yeo, B. T. T., \& Holmes, A. J. (2020). Convergent molecular, cellular, and cortical 
neuroimaging signatures of major depressive disorder. Proceedings of the National Academy of Sciences. https://doi.org/10.1073/pnas.2008004117

Aquino, K. M., Fulcher, B. D., Parkes, L., Sabaroedin, K., \& Fornito, A. (2020). Identifying and removing widespread signal deflections from fMRI data: Rethinking the global signal regression problem. NeuroImage, 212, 116614. https://doi.org/10.1016/j.neuroimage.2020.116614

Arnatkeviciute, A., Fulcher, B., Bellgrove, M., \& Fornito, A. (2021). Where the genome meets the connectome: Understanding how genes shape human brain connectivity. PsyArXiv. https://doi.org/10.31234/osf.io/hqgz7

Arnatkeviciute, A., Fulcher, B. D., \& Fornito, A. (2019). A practical guide to linking brainwide gene expression and neuroimaging data. NeuroImage, 189, 353-367. https://doi.org/10.1016/j.neuroimage.2019.01.011

Arnatkeviciute, A., Fulcher, B. D., Oldham, S., Tiego, J., Paquola, C., Gerring, Z., Aquino, K., Hawi, Z., Johnson, B., Ball, G., Klein, M., Deco, G., Franke, B., Bellgrove, M. A., \& Fornito, A. (2021). Genetic influences on hub connectivity of the human connectome. Nature Communications, 12(1), 4237. https://doi.org/10.1038/s41467$021-24306-2$

Arnatkeviciute, A., Fulcher, B. D., Pocock, R., \& Fornito, A. (2018). Hub connectivity, neuronal diversity, and gene expression in the Caenorhabditis elegans connectome. PLOS Computational Biology, 14(2), e1005989.

https://doi.org/10.1371/journal.pcbi.1005989

Ashburner, M., Ball, C. A., Blake, J. A., Botstein, D., Butler, H., Cherry, J. M., Davis, A. P., Dolinski, K., Dwight, S. S., Eppig, J. T., Harris, M. A., Hill, D. P., Issel-Tarver, L., Kasarskis, A., Lewis, S., Matese, J. C., Richardson, J. E., Ringwald, M., Rubin, G. 
M., \& Sherlock, G. (2000). Gene Ontology: Tool for the unification of biology. Nature Genetics, 25(1), 25-29. https://doi.org/10.1038/75556

Baaré, W. F. C., Hulshoff Pol, H. E., Boomsma, D. I., Posthuma, D., de Geus, E. J. C., Schnack, H. G., van Haren, N. E. M., van Oel, C. J., \& Kahn, R. S. (2001). Quantitative Genetic Modeling of Variation in Human Brain Morphology. Cerebral Cortex, 11(9), 816-824. https://doi.org/10.1093/cercor/11.9.816

Ball, G., Seidlitz, J., Beare, R., \& Seal, M. L. (2020). Cortical remodelling in childhood is associated with genes enriched for neurodevelopmental disorders. NeuroImage, 215, 116803. https://doi.org/10.1016/j.neuroimage.2020.116803

Ballatore, C., Lee, V. M.-Y., \& Trojanowski, J. Q. (2007). Tau-mediated neurodegeneration in Alzheimer's disease and related disorders. Nature Reviews Neuroscience, 8(9), 663-672. https://doi.org/10.1038/nrn2194

Berchtold, N. C., Cribbs, D. H., Coleman, P. D., Rogers, J., Head, E., Kim, R., Beach, T., Miller, C., Troncoso, J., Trojanowski, J. Q., Zielke, H. R., \& Cotman, C. W. (2008). Gene expression changes in the course of normal brain aging are sexually dimorphic. Proceedings of the National Academy of Sciences, 105(40), 15605-15610.

Bigos, K. L., \& Weinberger, D. R. (2010). Imaging genetics-Days of future past. NeuroImage, 53(3), 804-809. https://doi.org/10.1016/j.neuroimage.2010.01.035

Botvinik-Nezer, R., Holzmeister, F., Camerer, C. F., Dreber, A., Huber, J., Johannesson, M., Kirchler, M., Iwanir, R., Mumford, J. A., Adcock, R. A., Avesani, P., Baczkowski, B. M., Bajracharya, A., Bakst, L., Ball, S., Barilari, M., Bault, N., Beaton, D., Beitner, J., ... Schonberg, T. (2020). Variability in the analysis of a single neuroimaging dataset by many teams. Nature, 582(7810), 84-88. https://doi.org/10.1038/s41586-020-2314- 
Brettschneider, J., Tredici, K. D., Lee, V. M.-Y., \& Trojanowski, J. Q. (2015). Spreading of pathology in neurodegenerative diseases: A focus on human studies. Nature Reviews Neuroscience, 16(2), 109-120. https://doi.org/10.1038/nrn3887

Burt, J. B., Demirtaş, M., Eckner, W. J., Navejar, N. M., Ji, J. L., Martin, W. J., Bernacchia, A., Anticevic, A., \& Murray, J. D. (2018). Hierarchy of transcriptomic specialization across human cortex captured by structural neuroimaging topography. Nature Neuroscience, 21(9), 1251-1259. https://doi.org/10.1038/s41593-018-0195-0

Burt, J. B., Helmer, M., Shinn, M., Anticevic, A., \& Murray, J. D. (2020). Generative modeling of brain maps with spatial autocorrelation. NeuroImage, 220, 117038. https://doi.org/10.1016/j.neuroimage.2020.117038

Choi, J. K., \& Kim, S. C. (2007). Environmental Effects on Gene Expression Phenotype Have Regional Biases in the Human Genome. Genetics, 175(4), 1607-1613. https://doi.org/10.1534/genetics.106.069047

Ciric, R., Wolf, D. H., Power, J. D., Roalf, D. R., Baum, G. L., Ruparel, K., Shinohara, R. T., Elliott, M. A., Eickhoff, S. B., Davatzikos, C., Gur, R. C., Gur, R. E., Bassett, D. S., \& Satterthwaite, T. D. (2017). Benchmarking of participant-level confound regression strategies for the control of motion artifact in studies of functional connectivity. NeuroImage, 154, 174-187. https://doi.org/10.1016/j.neuroimage.2017.03.020

Cole, S. W. (2009). Social Regulation of Human Gene Expression. Current Directions in Psychological Science, 18(3), 132-137. https://doi.org/10.1111/j.14678721.2009.01623.x

Cornblath, E. J., Li, H. L., Changolkar, L., Zhang, B., Brown, H. J., Gathagan, R. J., Olufemi, M. F., Trojanowski, J. Q., Bassett, D. S., Lee, V. M. Y., \& Henderson, M. X. (2021). Computational modeling of tau pathology spread reveals patterns of regional 
vulnerability and the impact of a genetic risk factor. Science Advances, 7(24), eabg6677. https://doi.org/10.1126/sciadv.abg6677

Deco, G., Kringelbach, M. L., Arnatkeviciute, A., Oldham, S., Sabaroedin, K., Rogasch, N. C., Aquino, K. M., \& Fornito, A. (2021). Dynamical consequences of regional heterogeneity in the brain's transcriptional landscape. Science Advances, 7(29), eabf4752. https://doi.org/10.1126/sciadv.abf4752

Desplats, P., Lee, H.-J., Bae, E.-J., Patrick, C., Rockenstein, E., Crews, L., Spencer, B., Masliah, E., \& Lee, S.-J. (2009). Inclusion formation and neuronal cell death through neuron-to-neuron transmission of $\alpha$-synuclein. Proceedings of the National Academy of Sciences, 106(31), 13010-13015.

Elliott, L. T., Sharp, K., Alfaro-Almagro, F., Shi, S., Miller, K. L., Douaud, G., Marchini, J., \& Smith, S. M. (2018). Genome-wide association studies of brain imaging phenotypes in UK Biobank. Nature, 562(7726), 210-216. https://doi.org/10.1038/s41586-018-0571-7

Forest, M., Iturria-Medina, Y., Goldman, J. S., Kleinman, C. L., Lovato, A., Klein, K. O., Evans, A., Ciampi, A., Labbe, A., \& Greenwood, C. M. T. (2017). Gene networks show associations with seed region connectivity. Human Brain Mapping, 38(6), 3126-3140. https://doi.org/10.1002/hbm.23579

Fornito, A., Arnatkevičiūtè, A., \& Fulcher, B. D. (2019). Bridging the Gap between Connectome and Transcriptome. Trends in Cognitive Sciences, 23(1), 34-50. https://doi.org/10.1016/j.tics.2018.10.005

Fornito, A., Zalesky, A., \& Breakspear, M. (2015). The connectomics of brain disorders. Nature Reviews Neuroscience, 16(3), 159-172. https://doi.org/10.1038/nrn3901 
Fornito, A., Zalesky, A., Pantelis, C., \& Bullmore, E. T. (2012). Schizophrenia, neuroimaging and connectomics. NeuroImage, 62(4), 2296-2314. https://doi.org/10.1016/j.neuroimage.2011.12.090

Fraser, H. B., Khaitovich, P., Plotkin, J. B., Pääbo, S., \& Eisen, M. B. (2005). Aging and Gene Expression in the Primate Brain. PLOS Biology, 3(9), e274. https://doi.org/10.1371/journal.pbio.0030274

Freeze, B., Acosta, D., Pandya, S., Zhao, Y., \& Raj, A. (2018). Regional expression of genes mediating trans-synaptic alpha-synuclein transfer predicts regional atrophy in Parkinson disease. NeuroImage. Clinical, 18, 456-466. https://doi.org/10.1016/j.nicl.2018.01.009

Freeze, B., Pandya, S., Zeighami, Y., \& Raj, A. (2019). Regional transcriptional architecture of Parkinson's disease pathogenesis and network spread. Brain: A Journal of Neurology, 142(10), 3072-3085. https://doi.org/10.1093/brain/awz223

Fulcher, B. D. (2019). Discovering Conserved Properties of Brain Organization Through Multimodal Integration and Interspecies Comparison. Journal of Experimental Neuroscience, 13, 1179069519862047. https://doi.org/10.1177/1179069519862047

Fulcher, B. D., Arnatkevičiūtè, A., \& Fornito, A. (2021). Overcoming bias in gene-set enrichment analyses of brain-wide transcriptomic data. Nature Communications (in Press). https://doi.org/10.1101/2020.04.24.058958

Fulcher, B. D., \& Fornito, A. (2016). A transcriptional signature of hub connectivity in the mouse connectome. Proceedings of the National Academy of Sciences, 113(5), 14351440. https://doi.org/10.1073/pnas.1513302113

Gao, R., van den Brink, R. L., Pfeffer, T., \& Voytek, B. (2020). Neuronal timescales are functionally dynamic and shaped by cortical microarchitecture. ELife, 9, e61277. https://doi.org/10.7554/eLife.61277 
Ge, T., Holmes, A. J., Buckner, R. L., Smoller, J. W., \& Sabuncu, M. R. (2017). Heritability analysis with repeat measurements and its application to resting-state functional connectivity. Proceedings of the National Academy of Sciences, 114(21), 5521-5526. https://doi.org/10.1073/pnas.1700765114

Giedd, J. N., \& Rapoport, J. L. (2010). Structural MRI of Pediatric Brain Development: What Have We Learned and Where Are We Going? Neuron, 67(5), 728-734. https://doi.org/10.1016/j.neuron.2010.08.040

Gilmore, J. H., Santelli, R. K., \& Gao, W. (2018). Imaging structural and functional brain development in early childhood. Nature Reviews. Neuroscience, 19(3), 123-137. https://doi.org/10.1038/nrn.2018.1

Gogtay, N., Vyas, N. S., Testa, R., Wood, S. J., \& Pantelis, C. (2011). Age of Onset of Schizophrenia: Perspectives From Structural Neuroimaging Studies. Schizophrenia Bulletin, 37(3), 504-513. https://doi.org/10.1093/schbul/sbr030

Gong, G., He, Y., Chen, Z. J., \& Evans, A. C. (2012). Convergence and divergence of thickness correlations with diffusion connections across the human cerebral cortex. NeuroImage, 59(2), 1239-1248. https://doi.org/10.1016/j.neuroimage.2011.08.017

Goulas, A., Uylings, H. B. M., \& Hilgetag, C. C. (2017). Principles of ipsilateral and contralateral cortico-cortical connectivity in the mouse. Brain Structure \& Function, 222(3), 1281-1295. https://doi.org/10.1007/s00429-016-1277-y

Goyal, M. S., Hawrylycz, M., Miller, J. A., Snyder, A. Z., \& Raichle, M. E. (2014). Aerobic glycolysis in the human brain is associated with development and neotenous gene expression. Cell Metabolism, 19(1), 49-57. https://doi.org/10.1016/j.cmet.2013.11.020 
Greenbaum, D., Colangelo, C., Williams, K., \& Gerstein, M. (2003). Comparing protein abundance and mRNA expression levels on a genomic scale. Genome Biology, 4(9), 117. https://doi.org/10.1186/gb-2003-4-9-117

Grothe, M. J., Sepulcre, J., Gonzalez-Escamilla, G., Jelistratova, I., Schöll, M., Hansson, O., Teipel, S. J., \& Alzheimer's Disease Neuroimaging Initiative. (2018). Molecular properties underlying regional vulnerability to Alzheimer's disease pathology. Brain: A Journal of Neurology, 141(9), 2755-2771. https://doi.org/10.1093/brain/awy189

Gygi, S. P., Rochon, Y., Franza, B. R., \& Aebersold, R. (1999). Correlation between protein and mRNA abundance in yeast. Molecular and Cellular Biology, 19(3), 1720-1730. https://doi.org/10.1128/MCB.19.3.1720

Häfner, H., Maurer, K., Löffler, W., Fätkenheuer, B., an der Heiden, W., Riecher-Rössler, A., Behrens, S., \& Gattaz, W. F. (1994). The epidemiology of early schizophrenia. Influence of age and gender on onset and early course. The British Journal of Psychiatry. Supplement, 23, 29-38.

Hansen, J. Y., Markello, R. D., Vogel, J. W., Seidlitz, J., Bzdok, D., \& Misic, B. (2021). Mapping gene transcription and neurocognition across human neocortex. Nature Human Behaviour, 1-11. https://doi.org/10.1038/s41562-021-01082-z

Harris, K. D., Hochgerner, H., Skene, N. G., Magno, L., Katona, L., Bengtsson Gonzales, C., Somogyi, P., Kessaris, N., Linnarsson, S., \& Hjerling-Leffler, J. (2018). Classes and continua of hippocampal CA1 inhibitory neurons revealed by single-cell transcriptomics. PLoS Biology, 16(6), e2006387. https://doi.org/10.1371/journal.pbio.2006387

Hashimoto, R., Ohi, K., Yamamori, H., Yasuda, Y., Fujimoto, M., Umeda-Yano, S., Watanabe, Y., Fukunaga, M., \& Takeda, M. (2015). Imaging Genetics and Psychiatric 
Disorders. Current Molecular Medicine, 15(2), 168-175.

https://doi.org/10.2174/1566524015666150303104159

Hawrylycz, M. J., Lein, E. S., Guillozet-Bongaarts, A. L., Shen, E. H., Ng, L., Miller, J. A., van de Lagemaat, L. N., Smith, K. A., Ebbert, A., Riley, Z. L., Abajian, C., Beckmann, C. F., Bernard, A., Bertagnolli, D., Boe, A. F., Cartagena, P. M., Chakravarty, M. M., Chapin, M., Chong, J., ... Jones, A. R. (2012). An anatomically comprehensive atlas of the adult human brain transcriptome. Nature, 489(7416), 391399. https://doi.org/10.1038/nature11405

Hawrylycz, M., Miller, J. A., Menon, V., Feng, D., Dolbeare, T., Guillozet-Bongaarts, A. L., Jegga, A. G., Aronow, B. J., Lee, C.-K., Bernard, A., Glasser, M. F., Dierker, D. L., Menche, J., Szafer, A., Collman, F., Grange, P., Berman, K. A., Mihalas, S., Yao, Z., ... Lein, E. (2015). Canonical genetic signatures of the adult human brain. Nature Neuroscience, 18(12), 1832-1844. https://doi.org/10.1038/nn.4171

Henderson, J. A., \& Robinson, P. A. (2014). Relations between the geometry of cortical gyrification and white-matter network architecture. Brain Connectivity, 4(2), 112130. https://doi.org/10.1089/brain.2013.0183

Hess, J. L., Akutagava-Martins, G. C., Patak, J. D., Glatt, S. J., \& Faraone, S. V. (2018). Why is there selective subcortical vulnerability in ADHD? Clues from postmortem brain gene expression data. Molecular Psychiatry, 23(8), 1787-1793. https://doi.org/10.1038/mp.2017.242

Hess, J. L., Radonjić, N. V., Patak, J., Glatt, S. J., \& Faraone, S. V. (2020). Autophagy, apoptosis, and neurodevelopmental genes might underlie selective brain region vulnerability in attention-deficit/hyperactivity disorder. Molecular Psychiatry. https://doi.org/10.1038/s41380-020-00974-2 
Heuvel, M. P. van den, Mandl, R. C. W., Stam, C. J., Kahn, R. S., \& Pol, H. E. H. (2010). Aberrant Frontal and Temporal Complex Network Structure in Schizophrenia: A Graph Theoretical Analysis. Journal of Neuroscience, 30(47), 15915-15926. https://doi.org/10.1523/JNEUROSCI.2874-10.2010

Hibar, D. P., Adams, H. H. H., Jahanshad, N., Chauhan, G., Stein, J. L., Hofer, E., Renteria, M. E., Bis, J. C., Arias-Vasquez, A., Ikram, M. K., Desrivières, S., Vernooij, M. W., Abramovic, L., Alhusaini, S., Amin, N., Andersson, M., Arfanakis, K., Aribisala, B. S., Armstrong, N. J., ... Ikram, M. A. (2017). Novel genetic loci associated with hippocampal volume. Nature Communications, 8(1), 13624. https://doi.org/10.1038/ncomms13624

Hibar, D. P., Stein, J. L., Renteria, M. E., Arias-Vasquez, A., Desrivières, S., Jahanshad, N., Toro, R., Wittfeld, K., Abramovic, L., Andersson, M., Aribisala, B. S., Armstrong, N. J., Bernard, M., Bohlken, M. M., Boks, M. P., Bralten, J., Brown, A. A., Chakravarty, M. M., Chen, Q., ... Medland, S. E. (2015). Common genetic variants influence human subcortical brain structures. Nature, 520(7546), 224-229. https://doi.org/10.1038/nature14101

Iş1ldak, U., Somel, M., Thornton, J. M., \& Dönertaş, H. M. (2020). Temporal changes in the gene expression heterogeneity during brain development and aging. Scientific Reports, 10(1), 4080. https://doi.org/10.1038/s41598-020-60998-0

Jansen, I. E., Savage, J. E., Watanabe, K., Bryois, J., Williams, D. M., Steinberg, S., Sealock, J., Karlsson, I. K., Hägg, S., Athanasiu, L., Voyle, N., Proitsi, P., Witoelar, A., Stringer, S., Aarsland, D., Almdahl, I. S., Andersen, F., Bergh, S., Bettella, F., ... Posthuma, D. (2019). Genome-wide meta-analysis identifies new loci and functional pathways influencing Alzheimer's disease risk. Nature Genetics, 51(3), 404-413. https://doi.org/10.1038/s41588-018-0311-9 
Jansen, P. R., Nagel, M., Watanabe, K., Wei, Y., Savage, J. E., Leeuw, C. A. de, Heuvel, M. P. van den, Sluis, S. van der, \& Posthuma, D. (2019). GWAS of brain volume on 54,407 individuals and cross-trait analysis with intelligence identifies shared genomic loci and genes. BioRxiv, 613489. https://doi.org/10.1101/613489

Ji, Y., Zhang, X., Wang, Z., Qin, W., Liu, H., Xue, K., Tang, J., Xu, Q., Zhu, D., Liu, F., \& Yu, C. (2021). Genes associated with gray matter volume alterations in schizophrenia. NeuroImage, 225, 117526. https://doi.org/10.1016/j.neuroimage.2020.117526

Johnson, E. B., Ziegler, G., Penny, W., Rees, G., Tabrizi, S. J., Scahill, R. I., \& Gregory, S. (2021). Dynamics of Cortical Degeneration Over a Decade in Huntington's Disease. Biological Psychiatry, 89(8), 807-816. https://doi.org/10.1016/j.biopsych.2020.11.009

Jucker, M., \& Walker, L. C. (2018). Propagation and spread of pathogenic protein assemblies in neurodegenerative diseases. Nature Neuroscience, 21(10), 1341-1349. https://doi.org/10.1038/s41593-018-0238-6

Kanehisa, M., \& Goto, S. (2000). KEGG: Kyoto Encyclopedia of Genes and Genomes. Nucleic Acids Research, 28(1), 27-30.

Kang, H. J., Kawasawa, Y. I., Cheng, F., Zhu, Y., Xu, X., Li, M., Sousa, A. M. M., Pletikos, M., Meyer, K. A., Sedmak, G., Guennel, T., Shin, Y., Johnson, M. B., Krsnik, Ž., Mayer, S., Fertuzinhos, S., Umlauf, S., Lisgo, S. N., Vortmeyer, A., ... Šestan, N. (2011). Spatio-temporal transcriptome of the human brain. Nature, 478(7370), 483489. https://doi.org/10.1038/nature10523

Kanherkar, R. R., Bhatia-Dey, N., \& Csoka, A. B. (2014). Epigenetics across the human lifespan. Frontiers in Cell and Developmental Biology, 2, 49. https://doi.org/10.3389/fcell.2014.00049 
Keil, J. M., Qalieh, A., \& Kwan, K. Y. (2018). Brain Transcriptome Databases: A User's Guide. The Journal of Neuroscience, 38(10), 2399-2412. https://doi.org/10.1523/JNEUROSCI.1930-17.2018

Khundrakpam, B. S., Lewis, J. D., Kostopoulos, P., Carbonell, F., \& Evans, A. C. (2017). Cortical Thickness Abnormalities in Autism Spectrum Disorders Through Late Childhood, Adolescence, and Adulthood: A Large-Scale MRI Study. Cerebral Cortex, 27(3), 1721-1731. https://doi.org/10.1093/cercor/bhx038

Knickmeyer, R. C., Gouttard, S., Kang, C., Evans, D., Wilber, K., Smith, J. K., Hamer, R. M., Lin, W., Gerig, G., \& Gilmore, J. H. (2008). A Structural MRI Study of Human Brain Development from Birth to 2 Years. The Journal of Neuroscience, 28(47), 12176-12182. https://doi.org/10.1523/JNEUROSCI.3479-08.2008

Krienen, F. M., Yeo, B. T. T., Ge, T., Buckner, R. L., \& Sherwood, C. C. (2016). Transcriptional profiles of supragranular-enriched genes associate with corticocortical network architecture in the human brain. Proceedings of the National Academy of Sciences, 113(4), E469-E478. https://doi.org/10.1073/pnas.1510903113

Lake, B. B., Ai, R., Kaeser, G. E., Salathia, N. S., Yung, Y. C., Liu, R., Wildberg, A., Gao, D., Fung, H.-L., Chen, S., Vijayaraghavan, R., Wong, J., Chen, A., Sheng, X., Kaper, F., Shen, R., Ronaghi, M., Fan, J.-B., Wang, W., ... Zhang, K. (2016). Neuronal subtypes and diversity revealed by single-nucleus RNA sequencing of the human brain. Science, 352(6293), 1586-1590. https://doi.org/10.1126/science.aaf1204

Lau, H. Y. G., Fornito, A., \& Fulcher, B. D. (2021). Scaling of gene transcriptional gradients with brain size across mouse development. NeuroImage, 224, 117395. https://doi.org/10.1016/j.neuroimage.2020.117395

Lein, E. S., Hawrylycz, M. J., Ao, N., Ayres, M., Bensinger, A., Bernard, A., Boe, A. F., Boguski, M. S., Brockway, K. S., Byrnes, E. J., Chen, L., Chen, L., Chen, T.-M., Chi 
Chin, M., Chong, J., Crook, B. E., Czaplinska, A., Dang, C. N., Datta, S., ... Jones, A. R. (2007). Genome-wide atlas of gene expression in the adult mouse brain. Nature, 445(7124), 168-176. https://doi.org/10.1038/nature05453

Lewis, D. A., Curley, A. A., Glausier, J. R., \& Volk, D. W. (2012). Cortical parvalbumin interneurons and cognitive dysfunction in schizophrenia. Trends in Neurosciences, 35(1), 57-67. https://doi.org/10.1016/j.tins.2011.10.004

Li, J., Seidlitz, J., Suckling, J., Fan, F., Ji, G.-J., Meng, Y., Yang, S., Wang, K., Qiu, J., Chen, H., \& Liao, W. (2021). Cortical structural differences in major depressive disorder correlate with cell type-specific transcriptional signatures. Nature Communications, 12(1), 1647. https://doi.org/10.1038/s41467-021-21943-5

Liu, F., Tian, H., Li, J., Li, S., \& Zhuo, C. (2019). Altered voxel-wise gray matter structural brain networks in schizophrenia: Association with brain genetic expression pattern. Brain Imaging and Behavior, 13(2), 493-502. https://doi.org/10.1007/s11682-018$9880-6$

Lu, F.-P., Lin, K.-P., \& Kuo, H.-K. (2009). Diabetes and the Risk of Multi-System Aging Phenotypes: A Systematic Review and Meta-Analysis. PLOS ONE, 4(1), e4144. https://doi.org/10.1371/journal.pone.0004144

Mancarci, B. O., Toker, L., Tripathy, S. J., Li, B., Rocco, B., Sibille, E., \& Pavlidis, P. (2017). Cross-Laboratory Analysis of Brain Cell Type Transcriptomes with Applications to Interpretation of Bulk Tissue Data. ENeuro, 4(6). https://doi.org/10.1523/ENEURO.0212-17.2017

Markello, R. (2021). Rmarkello/abagen [Python]. https://github.com/rmarkello/abagen (Original work published 2018) 
Markello, R. D., Arnatkevičiūtè, A., Poline, J.-B., Fulcher, B. D., Fornito, A., \& Misic, B. (2021). Standardizing workflows in imaging transcriptomics with the abagen toolbox. BioRxiv, 2021.07.08.451635. https://doi.org/10.1101/2021.07.08.451635

Markello, R. D., \& Misic, B. (2020). Comparing spatially-constrained null models for parcellated brain maps. BioRxiv, 2020.08.13.249797. https://doi.org/10.1101/2020.08.13.249797

McColgan, P., Gregory, S., Seunarine, K. K., Razi, A., Papoutsi, M., Johnson, E., Durr, A., Roos, R. A. C., Leavitt, B. R., Holmans, P., Scahill, R. I., Clark, C. A., Rees, G., Tabrizi, S. J., Coleman, A., Decolongon, J., Fan, M., Petkau, T., Jauffret, C., ... Crawfurd, D. (2018). Brain Regions Showing White Matter Loss in Huntington's Disease Are Enriched for Synaptic and Metabolic Genes. Biological Psychiatry, 83(5), 456-465. https://doi.org/10.1016/j.biopsych.2017.10.019

Miller, J. A., Ding, S.-L., Sunkin, S. M., Smith, K. A., Ng, L., Szafer, A., Ebbert, A., Riley, Z. L., Royall, J. J., Aiona, K., Arnold, J. M., Bennet, C., Bertagnolli, D., Brouner, K., Butler, S., Caldejon, S., Carey, A., Cuhaciyan, C., Dalley, R. A., ... Lein, E. S. (2014). Transcriptional landscape of the prenatal human brain. Nature, 508(7495), 199-206. https://doi.org/10.1038/nature13185

Morgan, S. E., Seidlitz, J., Whitaker, K. J., Romero-Garcia, R., Clifton, N. E., Scarpazza, C., van Amelsvoort, T., Marcelis, M., van Os, J., Donohoe, G., Mothersill, D., Corvin, A., Pocklington, A., Raznahan, A., McGuire, P., Vértes, P. E., \& Bullmore, E. T. (2019). Cortical patterning of abnormal morphometric similarity in psychosis is associated with brain expression of schizophrenia-related genes. Proceedings of the National Academy of Sciences of the United States of America, 116(19), 9604-9609. https://doi.org/10.1073/pnas.1820754116

Myers, R. H. (2004). Huntington's Disease Genetics. NeuroRx, 1(2), 255-262. 
Narr, K. L., Woods, R. P., Lin, J., Kim, J., Phillips, O. R., Del'Homme, M., Caplan, R., Toga, A. W., McCracken, J. T., \& Levitt, J. G. (2009). Widespread Cortical Thinning Is a Robust Anatomical Marker for Attention Deficit / Hyperactivity Disorder (ADHD). Journal of the American Academy of Child and Adolescent Psychiatry, 48(10), 10141022. https://doi.org/10.1097/CHI.0b013e3181b395c0

Natu, V. S., Gomez, J., Barnett, M., Jeska, B., Kirilina, E., Jaeger, C., Zhen, Z., Cox, S., Weiner, K. S., Weiskopf, N., \& Grill-Spector, K. (2019). Apparent thinning of human visual cortex during childhood is associated with myelination. Proceedings of the National Academy of Sciences, 116(41), 20750-20759.

Niu, M., Wang, Y., Jia, Y., Wang, J., Zhong, S., Lin, J., Sun, Y., Zhao, L., Liu, X., Huang, L., \& Huang, R. (2017). Common and Specific Abnormalities in Cortical Thickness in Patients with Major Depressive and Bipolar Disorders. EBioMedicine, 16, 162171. https://doi.org/10.1016/j.ebiom.2017.01.010

Oldham, M. C., Konopka, G., Iwamoto, K., Langfelder, P., Kato, T., Horvath, S., \& Geschwind, D. H. (2008). Functional organization of the transcriptome in human brain. Nature Neuroscience, 11(11), 1271-1282. https://doi.org/10.1038/nn.2207

Oldham, S., Arnatkevičiūtè, A., Smith, R. E., Tiego, J., Bellgrove, M. A., \& Fornito, A. (2020). The efficacy of different preprocessing steps in reducing motion-related confounds in diffusion MRI connectomics. NeuroImage, 117252. https://doi.org/10.1016/j.neuroimage.2020.117252

Pandya, S., Zeighami, Y., Freeze, B., Dadar, M., Collins, D. L., Dagher, A., \& Raj, A. (2019). Predictive model of spread of Parkinson's pathology using network diffusion. NeuroImage, 192, 178-194. https://doi.org/10.1016/j.neuroimage.2019.03.001 
Pantazatos, S. P., \& Li, X. (2017). Commentary: BRAIN NETWORKS. Correlated Gene Expression Supports Synchronous Activity in Brain Networks. Science 348, 1241-4. Frontiers in Neuroscience, 11. https://doi.org/10.3389/fnins.2017.00412 Parker, N., Patel, Y., Jackowski, A. P., Pan, P. M., Salum, G. A., Pausova, Z., Paus, T., \& Saguenay Youth Study and the IMAGEN Consortium. (2020). Assessment of Neurobiological Mechanisms of Cortical Thinning During Childhood and Adolescence and Their Implications for Psychiatric Disorders. JAMA Psychiatry, 77(11), 1127-1136. https://doi.org/10.1001/jamapsychiatry.2020.1495

Parkes, L., Fulcher, B., Yücel, M., \& Fornito, A. (2018). An evaluation of the efficacy, reliability, and sensitivity of motion correction strategies for resting-state functional MRI. NeuroImage, 171, 415-436. https://doi.org/10.1016/j.neuroimage.2017.12.073

Patel, Y., Shin, J., Gowland, P. A., Pausova, Z., Paus, T., \& IMAGEN consortium. (2019). Maturation of the Human Cerebral Cortex During Adolescence: Myelin or Dendritic Arbor? Cerebral Cortex, 29(8), 3351-3362. https://doi.org/10.1093/cercor/bhy204

Patel, Yash, Autism Spectrum Disorder, Bipolar Disorder, Major Depressive Disorder, Obsessive-Compulsive Disorder, and Schizophrenia ENIGMA Working Groups, Patel, Y., Parker, N., Shin, J., Howard, D., French, L., Thomopoulos, S. I., Pozzi, E., Abe, Y., Abé, C., Anticevic, A., Alda, M., Aleman, A., Alloza, C., ... Paus, T. (2021). Virtual Histology of Cortical Thickness and Shared Neurobiology in 6 Psychiatric Disorders. JAMA Psychiatry, 78(1), 47-63.

https://doi.org/10.1001/jamapsychiatry.2020.2694

Pizzagalli, F., Auzias, G., Yang, Q., Mathias, S. R., Faskowitz, J., Boyd, J. D., Amini, A., Rivière, D., McMahon, K. L., de Zubicaray, G. I., Martin, N. G., Mangin, J.-F., Glahn, D. C., Blangero, J., Wright, M. J., Thompson, P. M., Kochunov, P., \& Jahanshad, N. (2020). The reliability and heritability of cortical folds and their genetic 
correlations across hemispheres. Communications Biology, 3(1), 1-12.

https://doi.org/10.1038/s42003-020-01163-1

Raj, A., Kuceyeski, A., \& Weiner, M. (2012). A network diffusion model of disease progression in dementia. Neuron, 73(6), 1204-1215. https://doi.org/10.1016/j.neuron.2011.12.040

Richiardi, J., Altmann, A., \& Greicius, M. (2017). Distance is not everything in imaging genomics of functional networks: Reply to a commentary on Correlated gene expression supports synchronous activity in brain networks. BioRxiv, 132746. https://doi.org/10.1101/132746

Richiardi, J., Altmann, A., Milazzo, A.-C., Chang, C., Chakravarty, M. M., Banaschewski, T., Barker, G. J., Bokde, A. L. W., Bromberg, U., Büchel, C., Conrod, P., FauthBühler, M., Flor, H., Frouin, V., Gallinat, J., Garavan, H., Gowland, P., Heinz, A., Lemaître, H., ... Consortium, I. (2015). Correlated gene expression supports synchronous activity in brain networks. Science, 348(6240), 1241-1244. https://doi.org/10.1126/science.1255905

Rittman, T., Rubinov, M., Vértes, P. E., Patel, A. X., Ginestet, C. E., Ghosh, B. C. P., Barker, R. A., Spillantini, M. G., Bullmore, E. T., \& Rowe, J. B. (2016). Regional expression of the MAPT gene is associated with loss of hubs in brain networks and cognitive impairment in Parkinson disease and progressive supranuclear palsy. Neurobiology of Aging, 48, 153-160. https://doi.org/10.1016/j.neurobiolaging.2016.09.001

Roberts, J. A., Perry, A., Lord, A. R., Roberts, G., Mitchell, P. B., Smith, R. E., Calamante, F., \& Breakspear, M. (2016). The contribution of geometry to the human connectome. NeuroImage, 124, 379-393. https://doi.org/10.1016/j.neuroimage.2015.09.009

Romero-Garcia, R., Seidlitz, J., Whitaker, K. J., Morgan, S. E., Fonagy, P., Dolan, R. J., Jones, P. B., Goodyer, I. M., Suckling, J., NSPN Consortium, Vértes, P. E., \& 
Bullmore, E. T. (2020). Schizotypy-Related Magnetization of Cortex in Healthy Adolescence Is Colocated With Expression of Schizophrenia-Related Genes. Biological Psychiatry, 88(3), 248-259. https://doi.org/10.1016/j.biopsych.2019.12.005

Romero-Garcia, R., Warrier, V., Bullmore, E. T., Baron-Cohen, S., \& Bethlehem, R. A. I. (2019). Synaptic and transcriptionally downregulated genes are associated with cortical thickness differences in autism. Molecular Psychiatry, 24(7), 1053-1064. https://doi.org/10.1038/s41380-018-0023-7

Romero-Garcia, R., Whitaker, K. J., Váša, F., Seidlitz, J., Shinn, M., Fonagy, P., Dolan, R. J., Jones, P. B., Goodyer, I. M., Bullmore, E. T., \& Vértes, P. E. (2018). Structural covariance networks are coupled to expression of genes enriched in supragranular layers of the human cortex. NeuroImage, 171, 256-267. https://doi.org/10.1016/j.neuroimage.2017.12.060

Romme, I. A. C., de Reus, M. A., Ophoff, R. A., Kahn, R. S., \& van den Heuvel, M. P. (2017). Connectome Disconnectivity and Cortical Gene Expression in Patients With Schizophrenia. Biological Psychiatry, 81(6), 495-502. https://doi.org/10.1016/j.biopsych.2016.07.012

Roshchupkin, G. V., Adams, H. H., van der Lee, S. J., Vernooij, M. W., van Duijn, C. M., Uitterlinden, A. G., van der Lugt, A., Hofman, A., Niessen, W. J., \& Ikram, M. A. (2016). Fine-mapping the effects of Alzheimer's disease risk loci on brain morphology. Neurobiology of Aging, 48, 204-211. https://doi.org/10.1016/j.neurobiolaging.2016.08.024

Salvador, R., Suckling, J., Coleman, M. R., Pickard, J. D., Menon, D., \& Bullmore, E. (2005). Neurophysiological Architecture of Functional Magnetic Resonance Images 
of Human Brain. Cerebral Cortex, 15(9), 1332-1342.

https://doi.org/10.1093/cercor/bhi016

Satizabal, C. L., Adams, H. H. H., Hibar, D. P., White, C. C., Knol, M. J., Stein, J. L., Scholz, M., Sargurupremraj, M., Jahanshad, N., Roshchupkin, G. V., Smith, A. V., Bis, J. C., Jian, X., Luciano, M., Hofer, E., Teumer, A., van der Lee, S. J., Yang, J., Yanek, L. R., ... Ikram, M. A. (2019). Genetic architecture of subcortical brain structures in 38,851 individuals. Nature Genetics, 51(11), 1624-1636.

https://doi.org/10.1038/s41588-019-0511-y

Schmierer, K., Scaravilli, F., Altmann, D. R., Barker, G. J., \& Miller, D. H. (2004).

Magnetization transfer ratio and myelin in postmortem multiple sclerosis brain. Annals of Neurology, 56(3), 407-415. https://doi.org/10.1002/ana.20202

Schulze, A., \& Downward, J. (2001). Navigating gene expression using microarrays-A technology review. Nature Cell Biology, 3(8), E190-195. https://doi.org/10.1038/35087138

Schwanhäusser, B., Busse, D., Li, N., Dittmar, G., Schuchhardt, J., Wolf, J., Chen, W., \& Selbach, M. (2011). Global quantification of mammalian gene expression control. Nature, 473(7347), 337-342. https://doi.org/10.1038/nature10098

Seeley, W. W. (2017). Mapping Neurodegenerative Disease Onset and Progression. Cold Spring Harbor Perspectives in Biology, 9(8), a023622.

https://doi.org/10.1101/cshperspect.a023622

Seidlitz, J., Nadig, A., Liu, S., Bethlehem, R. A. I., Vértes, P. E., Morgan, S. E., Váša, F., Romero-Garcia, R., Lalonde, F. M., Clasen, L. S., Blumenthal, J. D., Paquola, C., Bernhardt, B., Wagstyl, K., Polioudakis, D., Torre-Ubieta, L. de la, Geschwind, D. H., Han, J. C., Lee, N. R., ... Raznahan, A. (2020). Transcriptomic and cellular 
decoding of regional brain vulnerability to neurogenetic disorders. Nature Communications, 11(1), 1-14. https://doi.org/10.1038/s41467-020-17051-5

Seidlitz, J., Váša, F., Shinn, M., Romero-Garcia, R., Whitaker, K. J., Vértes, P. E., Wagstyl, K., Kirkpatrick Reardon, P., Clasen, L., Liu, S., Messinger, A., Leopold, D. A., Fonagy, P., Dolan, R. J., Jones, P. B., Goodyer, I. M., NSPN Consortium, Raznahan, A., \& Bullmore, E. T. (2018). Morphometric Similarity Networks Detect Microscale Cortical Organization and Predict Inter-Individual Cognitive Variation. Neuron, 97(1), 231-247.e7. https://doi.org/10.1016/j.neuron.2017.11.039

Selvaggi, P., Rizzo, G., Mehta, M. A., Turkheimer, F. E., \& Veronese, M. (2021). Integration of human whole-brain transcriptome and neuroimaging data: Practical considerations of current available methods. Journal of Neuroscience Methods, 355, 109128. https://doi.org/10.1016/j.jneumeth.2021.109128

Shen, K.-K., Rose, S., Fripp, J., McMahon, K. L., de Zubicaray, G. I., Martin, N. G., Thompson, P. M., Wright, M. J., \& Salvado, O. (2014). Investigating brain connectivity heritability in a twin study using diffusion imaging data. NeuroImage, 100, 628-641. https://doi.org/10.1016/j.neuroimage.2014.06.041

Shin, J., French, L., Xu, T., Leonard, G., Perron, M., Pike, G. B., Richer, L., Veillette, S., Pausova, Z., \& Paus, T. (2018). Cell-Specific Gene-Expression Profiles and Cortical Thickness in the Human Brain. Cerebral Cortex (New York, N.Y.: 1991), 28(9), 3267-3277. https://doi.org/10.1093/cercor/bhx197

Smith, S. M., Douaud, G., Chen, W., Hanayik, T., Alfaro-Almagro, F., Sharp, K., \& Elliott, L. T. (2020). Enhanced Brain Imaging Genetics in UK Biobank. BioRxiv, 2020.07.27.223545. https://doi.org/10.1101/2020.07.27.223545

Smith, S. M., Douaud, G., Chen, W., Hanayik, T., Alfaro-Almagro, F., Sharp, K., \& Elliott, L. T. (2021). An expanded set of genome-wide association studies of brain imaging 
phenotypes in UK Biobank. Nature Neuroscience, 24(5), 737-745.

https://doi.org/10.1038/s41593-021-00826-4

Sousa, A. M. M., Zhu, Y., Raghanti, M. A., Kitchen, R. R., Onorati, M., Tebbenkamp, A. T. N., Stutz, B., Meyer, K. A., Li, M., Kawasawa, Y. I., Liu, F., Perez, R. G., Mele, M., Carvalho, T., Skarica, M., Gulden, F. O., Pletikos, M., Shibata, A., Stephenson, A. R., ... Sestan, N. (2017). Molecular and cellular reorganization of neural circuits in the human lineage. Science, 358(6366), 1027-1032.

https://doi.org/10.1126/science.aan3456

Stephan, K. E., Friston, K. J., \& Frith, C. D. (2009). Dysconnection in Schizophrenia: From Abnormal Synaptic Plasticity to Failures of Self-monitoring. Schizophrenia Bulletin, 35(3), 509-527. https://doi.org/10.1093/schbul/sbn176

Subramanian, A., Tamayo, P., Mootha, V. K., Mukherjee, S., Ebert, B. L., Gillette, M. A., Paulovich, A., Pomeroy, S. L., Golub, T. R., Lander, E. S., \& Mesirov, J. P. (2005). Gene set enrichment analysis: A knowledge-based approach for interpreting genomewide expression profiles. Proceedings of the National Academy of Sciences, 102(43), 15545-15550. https://doi.org/10.1073/pnas.0506580102

Suh, J. S., Schneider, M. A., Minuzzi, L., MacQueen, G. M., Strother, S. C., Kennedy, S. H., \& Frey, B. N. (2019). Cortical thickness in major depressive disorder: A systematic review and meta-analysis. Progress in Neuro-Psychopharmacology \& Biological Psychiatry, 88, 287-302. https://doi.org/10.1016/j.pnpbp.2018.08.008

Tamnes, C. K., Herting, M. M., Goddings, A.-L., Meuwese, R., Blakemore, S.-J., Dahl, R. E., Güroğlu, B., Raznahan, A., Sowell, E. R., Crone, E. A., \& Mills, K. L. (2017). Development of the Cerebral Cortex across Adolescence: A Multisample Study of Inter-Related Longitudinal Changes in Cortical Volume, Surface Area, and 
Thickness. The Journal of Neuroscience, 37(12), 3402-3412.

https://doi.org/10.1523/JNEUROSCI.3302-16.2017

Thomas, G. E. C., Zarkali, A., Ryten, M., Shmueli, K., Martinez, A. L. G., Leyland, L.-A., McColgan, P., Acosta-Cabronero, J., Lees, A. J., \& Weil, R. S. (2021). Regional brain iron and gene expression provide insights into neurodegeneration in Parkinson's disease. Brain: A Journal of Neurology. https://doi.org/10.1093/brain/awab084

Thompson, P. M., Cannon, T. D., Narr, K. L., van Erp, T., Poutanen, V.-P., Huttunen, M., Lönnqvist, J., Standertskjöld-Nordenstam, C.-G., Kaprio, J., Khaledy, M., Dail, R., Zoumalan, C. I., \& Toga, A. W. (2001). Genetic influences on brain structure. Nature Neuroscience, 4(12), 1253-1258. https://doi.org/10.1038/nn758

Thompson, P. M., Ge, T., Glahn, D. C., Jahanshad, N., \& Nichols, T. E. (2013). Genetics of the connectome. NeuroImage, $80,475-488$.

https://doi.org/10.1016/j.neuroimage.2013.05.013

van Haren, N. E. M., Schnack, H. G., Cahn, W., van den Heuvel, M. P., Lepage, C., Collins, L., Evans, A. C., Hulshoff Pol, H. E., \& Kahn, R. S. (2011). Changes in cortical thickness during the course of illness in schizophrenia. Archives of General Psychiatry, 68(9), 871-880. https://doi.org/10.1001/archgenpsychiatry.2011.88

Váša, F., Seidlitz, J., Romero-Garcia, R., Whitaker, K. J., Rosenthal, G., Vértes, P. E., Shinn, M., Alexander-Bloch, A., Fonagy, P., Dolan, R. J., Jones, P. B., Goodyer, I. M., Consortium, the N., Sporns, O., \& Bullmore, E. T. (2018). Adolescent Tuning of Association Cortex in Human Structural Brain Networks. Cerebral Cortex, 28(1), 281-294. https://doi.org/10.1093/cercor/bhx249

Vértes, P. E., Rittman, T., Whitaker, K. J., Romero-Garcia, R., Váša, F., Kitzbichler, M. G., Wagstyl, K., Fonagy, P., Dolan, R. J., Jones, P. B., Goodyer, I. M., \& Bullmore, E. T. (2016). Gene transcription profiles associated with inter-modular hubs and connection 
distance in human functional magnetic resonance imaging networks. Philosophical Transactions of the Royal Society B: Biological Sciences, 371(1705).

https://doi.org/10.1098/rstb.2015.0362

Vidal-Pineiro, D., Parker, N., Shin, J., French, L., Grydeland, H., Jackowski, A. P., Mowinckel, A. M., Patel, Y., Pausova, Z., Salum, G., Sørensen, Ø., Walhovd, K. B., Paus, T., Fjell, A. M., \& Alzheimer's Disease Neuroimaging Initiative and the Australian Imaging Biomarkers and Lifestyle flagship study of ageing. (2020). Cellular correlates of cortical thinning throughout the lifespan. Scientific Reports, 10(1), 21803. https://doi.org/10.1038/s41598-020-78471-3

Wei, Y., Lange, S. C. de, Pijnenburg, R., Scholtens, L. H., Ardesch, D. J., Watanabe, K., Posthuma, D., \& Heuvel, M. P. van den. (2021). Statistical testing and annotation of gene transcriptomic-neuroimaging associations. BioRxiv, 2021.02.22.432228. https://doi.org/10.1101/2021.02.22.432228

Whitaker, K. J., Vértes, P. E., Romero-Garcia, R., Váša, F., Moutoussis, M., Prabhu, G., Weiskopf, N., Callaghan, M. F., Wagstyl, K., Rittman, T., Tait, R., Ooi, C., Suckling, J., Inkster, B., Fonagy, P., Dolan, R. J., Jones, P. B., Goodyer, I. M., Consortium, the N., \& Bullmore, E. T. (2016). Adolescence is associated with genomically patterned consolidation of the hubs of the human brain connectome. Proceedings of the National Academy of Sciences, 113(32), 9105-9110. https://doi.org/10.1073/pnas.1601745113

Xie, Y., Zhang, X., Liu, F., Qin, W., Fu, J., Xue, K., \& Yu, C. (2020). Brain mRNA Expression Associated with Cortical Volume Alterations in Autism Spectrum Disorder. Cell Reports, 32(11), 108137. https://doi.org/10.1016/j.celrep.2020.108137 Xue, K., Liang, S., Yang, B., Zhu, D., Xie, Y., Qin, W., Liu, F., Zhang, Y., \& Yu, C. (2020). Local dynamic spontaneous brain activity changes in first-episode, treatment-naïve 
patients with major depressive disorder and their associated gene expression profiles. Psychological Medicine, 1-10. https://doi.org/10.1017/S0033291720003876

Yan, W., Ye, C., Wang, T., Sun, J., Wu, T., \& Ma, T. (2020). Misfolded protein propagation in an integrated computational model of structural network and LRRK2 gene expression. 2020 42nd Annual International Conference of the IEEE Engineering in Medicine Biology Society (EMBC), 2368-2371.

https://doi.org/10.1109/EMBC44109.2020.9178266

Yao, Z., van Velthoven, C. T. J., Nguyen, T. N., Goldy, J., Sedeno-Cortes, A. E., Baftizadeh, F., Bertagnolli, D., Casper, T., Chiang, M., Crichton, K., Ding, S.-L., Fong, O., Garren, E., Glandon, A., Gouwens, N. W., Gray, J., Graybuck, L. T., Hawrylycz, M. J., Hirschstein, D., ... Zeng, H. (2021). A taxonomy of transcriptomic cell types across the isocortex and hippocampal formation. Cell, 184(12), 3222-3241.e26. https://doi.org/10.1016/j.cell.2021.04.021

Zalesky, A., Fornito, A., Seal, M. L., Cocchi, L., Westin, C.-F., Bullmore, E. T., Egan, G. F., \& Pantelis, C. (2011). Disrupted Axonal Fiber Connectivity in Schizophrenia. Biological Psychiatry, 69(1), 80-89. https://doi.org/10.1016/j.biopsych.2010.08.022

Zeisel, A., Muñoz-Manchado, A. B., Codeluppi, S., Lönnerberg, P., Manno, G. L., Juréus, A., Marques, S., Munguba, H., He, L., Betsholtz, C., Rolny, C., Castelo-Branco, G., Hjerling-Leffler, J., \& Linnarsson, S. (2015). Cell types in the mouse cortex and hippocampus revealed by single-cell RNA-seq. Science, 347(6226), 1138-1142. https://doi.org/10.1126/science.aaa1934

Zhao, B., Luo, T., Li, T., Li, Y., Zhang, J., Shan, Y., Wang, X., Yang, L., Zhou, F., Zhu, Z., \& Zhu, H. (2019). Genome-wide association analysis of 19,629 individuals identifies variants influencing regional brain volumes and refines their genetic co-architecture 
with cognitive and mental health traits. Nature Genetics, 51(11), 1637-1644.

https://doi.org/10.1038/s41588-019-0516-6

Zheng, Y.-Q., Zhang, Y., Yau, Y., Zeighami, Y., Larcher, K., Misic, B., \& Dagher, A. (2019). Local vulnerability and global connectivity jointly shape neurodegenerative disease propagation. PLOS Biology, 17(11), e3000495.

https://doi.org/10.1371/journal.pbio.3000495 